\title{
A2B adenosine receptor signaling attenuates acute lung injury by enhancing alveolar fluid clearance in mice
}

\author{
Tobias Eckle,1,2 Almut Grenz,1,3 Stefanie Laucher,2 and Holger K. Eltzschig',2 \\ ${ }^{1}$ Mucosal Inflammation Program, Department of Anesthesiology and Perioperative Medicine, University of Colorado Health Sciences Center, \\ Denver, Colorado, USA. ${ }^{2}$ Department of Anesthesiology and Intensive Care Medicine and \\ ${ }^{3}$ Department of Pharmacology and Toxicology, Tübingen University Hospital, Tübingen, Germany.
}

\begin{abstract}
Although acute lung injury contributes significantly to critical illness, resolution often occurs spontaneously via activation of incompletely understood pathways. We recently found that mechanical ventilation of mice increases the level of pulmonary adenosine, and that mice deficient for extracellular adenosine generation show increased pulmonary edema and inflammation after ventilator-induced lung injury (VILI). Here, we profiled the response to VILI in mice with genetic deletions of each of the 4 adenosine receptors (ARs) and found that deletion of the $A 2 B A R$ gene was specifically associated with reduced survival time and increased pulmonary albumin leakage after injury. In WT mice, treatment with an A2BAR-selective antagonist resulted in enhanced pulmonary inflammation, edema, and attenuated gas exchange, while an A2BAR agonist attenuated VILI. In bone marrow-chimeric A2BAR mice, although the pulmonary inflammatory response involved A2BAR signaling from bone marrow-derived cells, A2BARs located on the lung tissue attenuated VILI-induced albumin leakage and pulmonary edema. Furthermore, measurement of alveolar fluid clearance (AFC) demonstrated that A2BAR signaling enhanced amiloride-sensitive fluid transport and elevation of pulmonary cAMP levels following VILI, suggesting that A2BAR agonist treatment protects by drying out the lungs. Similar enhancement of pulmonary cAMP and AFC were also observed after $\beta$-adrenergic stimulation, a pathway known to promote AFC. Taken together, these studies reveal a role for A2BAR signaling in attenuating VILI and implicate this receptor as a potential therapeutic target during acute lung injury.
\end{abstract}

\section{Introduction}

Acute lung injury (ALI) and acute respiratory distress syndrome (ARDS) are life-threatening disorders that can develop in the course of different clinical conditions such as pneumonia, acid aspiration, major trauma, or prolonged mechanical ventilation, and contribute significantly to critical illness (1). Recent epidemiological studies show that each year 75,000 patients in the United States alone die from ARDS (2). The pathogenesis of these diseases is characterized by influx of a protein-rich edema fluid into the interstitial and intraalveolar spaces as a consequence of increased permeability of the alveolar-capillary barrier (1) in conjunction with excessive invasion of inflammatory cells - particularly polymorphonuclear neutrophils (3-6). At present, only little is known about how to target the alveolar-capillary barrier function or leukocyte trafficking therapeutically during ALI. In fact, to our knowledge, no such strategies have been translated into clinical practice, and we are unaware of any specific therapy currently available beyond mechanical ventilation and other supportive measures (1).

Despite the large impact of ALI on morbidity and mortality in critically ill patients (1), many episodes are self-limiting and resolve spontaneously through unknown mechanisms. For example,

Nonstandard abbreviations used: AFC, alveolar fluid clearance; ALI, acute lung injury; AR, adenosine receptor; BAL, bronchoalveolar; ENaC, epithelial sodium channel; KC, keratinocyte-derived chemokine; MPO, myeloperoxidase; VILI, ventilatorinduced lung injury.

Conflict of interest: The authors have declared that no conflict of interest exists. Citation for this article: J. Clin. Invest. 118:3301-3315 (2008). doi:10.1172/JCI34203. patients undergoing major surgery requiring prolonged mechanical ventilation have an overall incidence of ALI between $0.2 \%$ and $5 \%$, depending on the kind of surgery (7-9). In a recent study to identify endogenous pathways to attenuate ventilator-induced lung injury (VILI), we found that extracellular adenosine accumulates in the supernatant of pulmonary epithelia exposed to cyclic mechanical stretch in vitro (10). Similarly, pulmonary adenosine levels were elevated during mechanical ventilation in vivo (10). In fact, mice deficient in extracellular adenosine production showed dramatic increases in pulmonary edema and pulmonary inflammation when exposed to VILI (10). However, adenosine-dependent signaling pathways of lung protection during VILI remain unknown. As such, extracellular adenosine can signal through any of $4 \mathrm{G}$ protein-coupled adenosine receptors (ARs), A1AR, A2AAR, A2BAR, and $\mathrm{A} 3 \mathrm{AR}$, which have all been implicated in tissue protection in different models of injury or inflammation (10-28). Therefore, we designed the present study to test the hypothesis that AR signaling plays an important role in VILI. For this purpose, we assessed VILI in genetic models for each individual AR. Because these studies pointed toward a pivotal role of A2BAR signaling, we confirmed these genetic studies using pharmacological approaches with specific A2BAR agonists and antagonists. Next, we created bone marrow chimeras to study A2BAR effects on hematopoietic versus nonhematopoietic cells. Finally, we pursued the contribution of A2BAR signaling to alveolar fluid clearance (AFC) during VILI. Taken together, these studies point toward a critical role of A2BAR signaling in attenuating VILI by dampening pulmonary inflammation, attenuation of pulmonary edema, and enhancement of amiloridesensitive fluid transport mechanisms to dry out the lungs. 

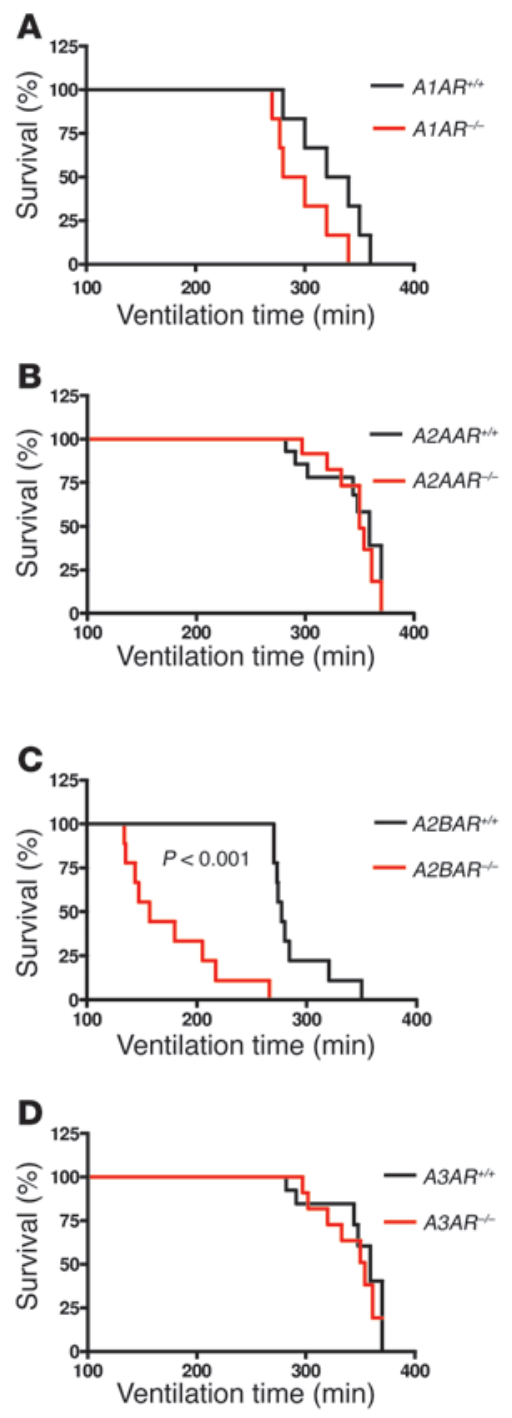

Figure 1

VILI in mice gene-targeted for individual ARs. Previously characterized $A 1 A R^{-/-}$ (A; ref. 29), $A 2 A A R^{-/-}$(B; ref. 30), $A 2 B A R^{-/-}$(C), or $A 3 A R^{-/-}$mice (D; ref. 22) or corresponding littermate controls were exposed to VILI, and survival times were determined during VILI. Mechanical ventilation was applied using pressure-controlled settings (inspiratory pressure of $35 \mathrm{mbar}$, inspired oxygen concentration $100 \%$; respiratory rate and inspiratory/expiratory ratio were adjusted to maintain normal $\mathrm{pH}$ ) until a cardiac standstill was observed in the surface electrocardiogram. Note the significantly attenuated survival of $A 2 B A R^{-1-}$ mice $(\mathbf{C} ; P<0.001$, $n=8$ ). Albumin concentration in the BAL fluid was determined by ELISA. For this purpose, the mice were mechanically ventilated using pressure-controlled ventilation with an inspired oxygen concentration of $100 \%$ for 180 minutes at $45 \mathrm{mbar}$. Note the significantly increased albumin concentration in the BAL fluid of $A 2 B A R^{-/-}$mice $(\mathbf{C} ; P<0.001, n=6)$.

\section{Results}

VILI is selectively enhanced in gene-targeted mice for the A2BAR. Based on previous studies showing extracellular adenosine generation in lung protection during VILI (10), we hypothesized that AR deficiency would significantly enhance pulmonary edema and attenuate survival during VILI. To this end, we exposed previously characterized mice that were gene-targeted for A1AR (29), A2AAR
(30), A2BAR (13), or A3AR (22) as well as corresponding age-, weight-, and gender-matched littermate controls to VILI. As shown in Figure 1, survival time during VILI or VILI-induced increases of albumin leakage into the bronchoalveolar (BAL) fluid were similar between $A 1 A R^{-/}$, $A 2 A A R^{-/-}$, and $A 3 A R^{-/-}$mice and their controls (Figure 1, $\mathrm{A}, \mathrm{B}$, and $\mathrm{D})$. In contrast, survival time was significantly shortened in $A 2 B A R^{-1-}$ mice (Figure $1 C ; P<0.001$ ), while albumin leakage into the BAL fluid was dramatically increased (Figure 1C; $P<0.001$ ). Taken together, these data indicate that specific genetic deletion of the A2BAR enhances murine VILI.

$A 2 B A R^{-1-}$ mice show increased pulmonary inflammation during VILI. To confirm our findings of enhanced VILI in $A 2 B A R^{-/-}$mice, we next measured additional functional parameters. Here, we found that increases in lung water content (Figure 2A; $P<0.01$ ) and attenuated gas exchange during VILI were enhanced in $A 2 B A R^{-/-}$ mice compared with controls $\left(A 2 B A R^{+/+}\right.$; Figure $2 \mathrm{~B}$; $P<0.01)$. Based on a recent study showing that A2BAR signaling attenuates pulmonary inflammation during acute hypoxia (31), we studied the influence of A2BAR signaling on pulmonary inflammation. As shown in Figure 2C, increases in pulmonary neutrophil numbers (as measured by myeloperoxidase [MPO]) with VILI were dramatically enhanced in $A 2 B A R^{-/-}$mice $(P<0.001)$. Similarly, increases in proinflammatory cytokines (pulmonary TNF- $\alpha$, IL- 6 , and keratinocytederived chemokine [KC, a mouse ortholog of human IL-8]) were enhanced (Figure 2, D-F; $P<0.001$ ), while levels of the antiinflammatory cytokine IL-10 (Figure $2 \mathrm{G} ; P<0.001$ ) were attenuated. Consistent with studies showing that pulmonary A2BAR signaling attenuates NF- $\mathrm{KB}$ activation via adenosine-mediated cullin-1 deneddylation (31), we pursued pulmonary NF-KB activation during VILI. Consistent with previous studies of mechanical stretch $(32,33)$, VILI was associated with a significant increase of pulmonary NF- $\mathrm{\kappa B}$ activity (Figure $2 \mathrm{H} ; P<0.001)$. However, pulmonary NF- $\mathrm{KB}$ activity was increased at baseline (Figure $2 \mathrm{H} ; P<0.001$ ), and VILI-induced increases of NF- $\kappa \mathrm{B}$ activity were further enhanced in $A 2 \mathrm{BAR}^{-/-}$mice (Figure $2 \mathrm{H} ; \mathrm{P}<0.001$ ). While a number of mechanisms have been suggested to mediate the endogenous inactivation of NF- $\mathrm{KB}$, each of these pathways converges on changes in the inducible degradation of I $\mathrm{B} \alpha$ (34). Thus, we determined whether A2BAR signaling influences I $\mathrm{B}$ activity during VILI. In fact, VILI-associated decreases in pulmonary IкB activity were accentuated in $A 2 B A R^{-1-}$ mice (Figure $2 \mathrm{I} ; P<0.001$ ), confirming a role of A2BAR signaling in attenuating $\mathrm{I} \kappa \mathrm{B} / \mathrm{NF}-\kappa \mathrm{B}-$ dependent pulmonary inflammation during VILI. To confirm increased susceptibility of $A 2 B A R^{-/-}$mice to lung injury on a histological level, we next examined lungs from $A 2 B A R^{-/}$and control mice after 180 minutes of ventilation at $45 \mathrm{mbar}$. As shown by VILI scores (Figure 2J) and in images from pulmonary sections (Figure $2 \mathrm{~K}$ ), histological signs of pulmonary injury associated with VILI were dramatically enhanced in $A 2 B A R^{-/-}$mice. Taken together, these results reveal increased pulmonary inflammation and severity of VILI associated with genetic deletion of A2BAR. 

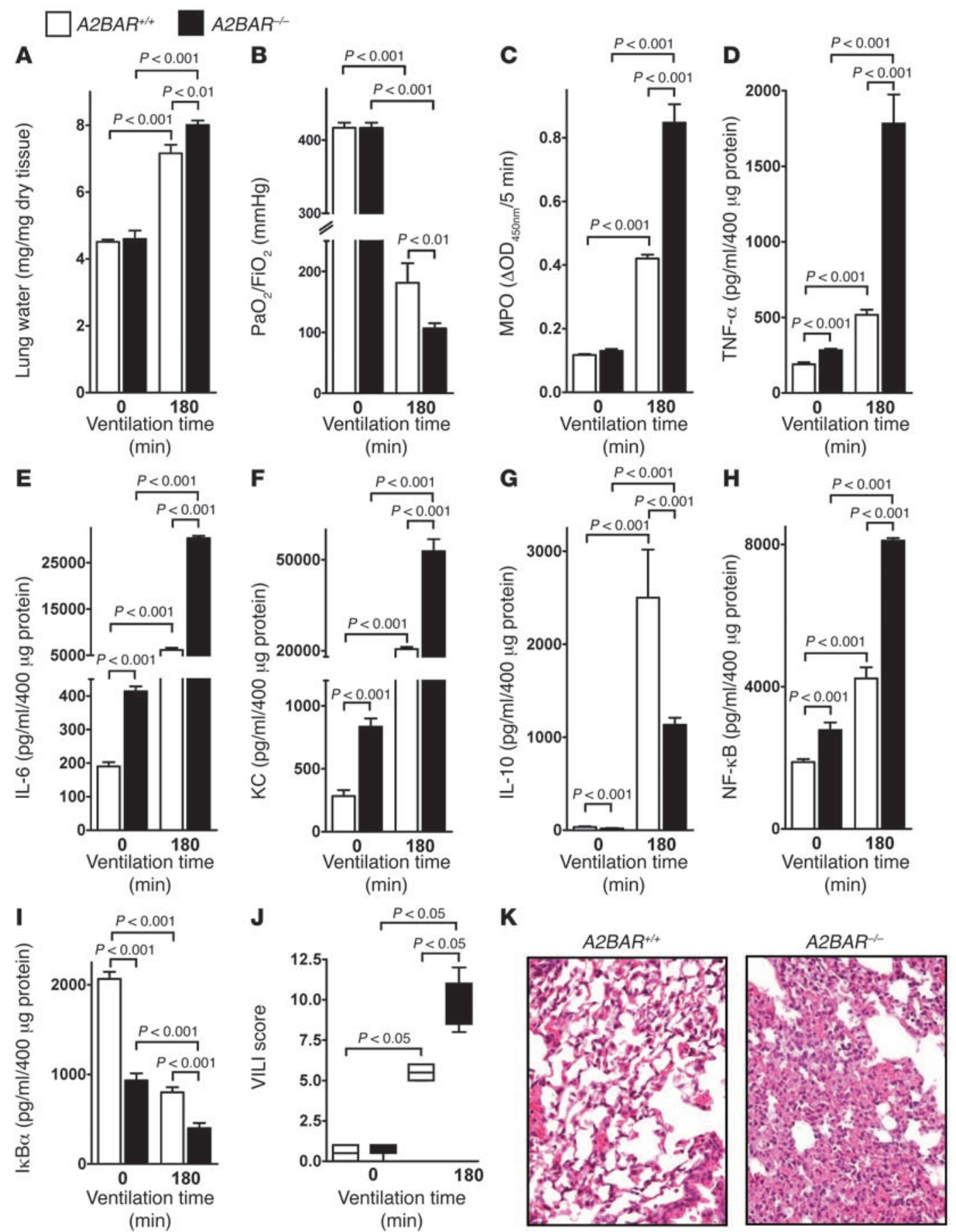

\section{Figure 2}

VILI in mice gene-targeted for the A2BAR. (A-H) $A 2 B A R^{-/-}$mice or littermate controls $\left(A 2 B A R^{+/+}\right)$were mechanically ventilated using pressurecontrolled ventilation with an inspired oxygen concentration of $100 \%$ over 180 minutes at $45 \mathrm{mbar}$. (A) Following ventilation, lungs were excised en bloc and weighed. Lungs were lyophilized for 48 hours, and lung water content (mg lung water/mg dry tissue) was determined. Results are presented as mean \pm SD $(n=6)$. (B) To assess pulmonary gas exchange, blood gas analyses were performed by obtaining arterial blood via cardiac puncture. Analysis was performed immediately, and the ratio of the arterial partial pressure of oxygen $\left(\mathrm{PaO}_{2}\right)$ to the fraction of inspired oxygen $\left(\mathrm{FiO}_{2}\right)$ was determined. Results are presented as mean $\pm \mathrm{SD}(n=6)$. (C) Pulmonary neutrophil accumulation was quantified using a MPO assay. MPO activity was assessed using a spectrophotometric reaction with $O$-dianisidine hydrochloride. Absorbance at $450 \mathrm{~nm}$ was measured and reported as difference in OD $(\Delta \mathrm{OD})$ over 5 minutes. Results are presented as mean \pm SD $(n=6)$. (D-I) TNF- $\alpha$, IL-6, KC, IL-10, NF- $\kappa B$, and IкB $\alpha$ levels were evaluated in lung tissue homogenates using a mouse ELISA. Results are presented as mean \pm SD $(n=6)$. (J) For quantification of histological tissue damage by VILI following 180 min ventilation, VILI scores were assessed in $A 2 B A R^{-/-}$or corresponding littermate control mice. Results are displayed as median (midline within boxes) and range (bars above and below boxes) $(n=4)$. (K) One of 4 representative photomicrographs (original magnification, $\times 200$ ) stained with hematoxylin and eosin is displayed. 

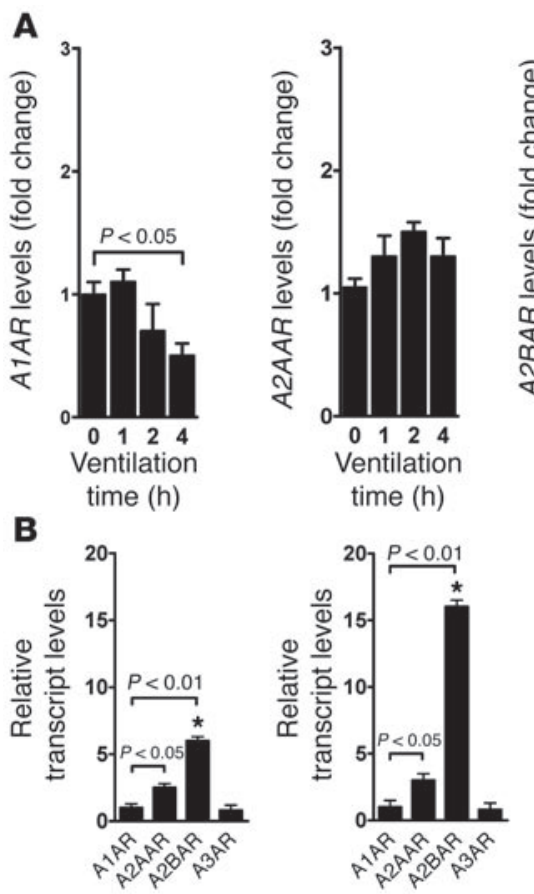

$0 \mathrm{~h}$ ventilation

$3 \mathrm{~h}$ ventilation

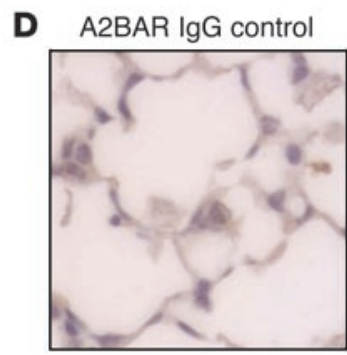

A2BAR $0 \mathrm{~h}$ ventilation

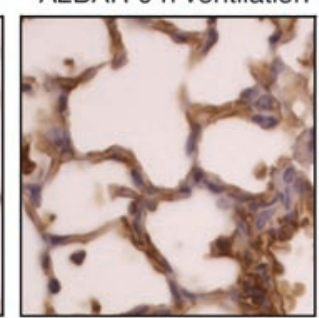

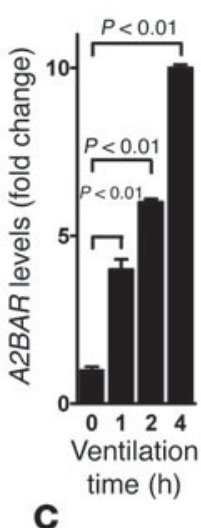
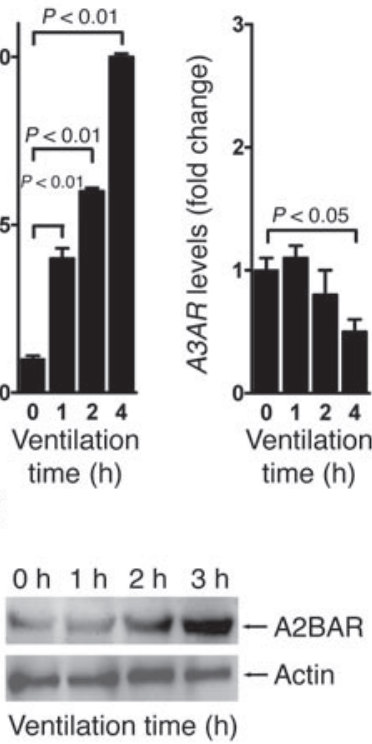

Ventilation time $(\mathrm{h})$

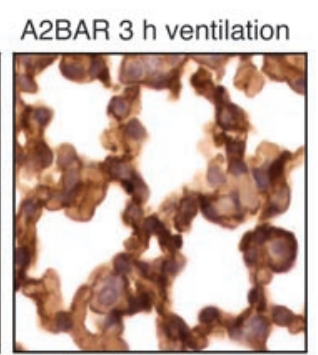

\section{Figure 3}

Transcriptional consequences of mechanical ventilation on AR expression. (A) C57BL/6 mice were mechanically ventilated (inspiratory pressure of $35 \mathrm{mbar}, 100 \%$ oxygen). After the indicated time periods, lungs were harvested, total RNA was isolated, and A1AR, A2AAR, A2BAR, and A3AR mRNA levels were determined by real-time RT-PCR. Data were calculated relative to the internal housekeeping gene $(\beta$-actin) and are expressed as mean fold change compared with control (0 min ventilation) $\pm \mathrm{SD}$ at each indicated time $(n=4)$. Note selective induction of the A2BAR gene during high-pressure ventilation (10-fold, $P<0.01 ; n=4)$. (B) Comparative gene expression of pulmonary ARs using realtime PCR. Relative expression levels in untreated controls or in mice after 180 min mechanical ventilation (inspiratory pressure of $35 \mathrm{mbar}, 100 \%$ oxygen) are shown. Values are expressed as mean $\pm \operatorname{SEM}(n=4)$. ${ }^{*} P<0.05$ compared with A2AAR. (C) Mice were mechanically ventilated (35 mbar inspiratory pressure, $100 \%$ oxygen), and lungs were harvested at the indicated time points, shock frozen, and lysed, and proteins were resolved by SDS-PAGE. Resultant western blots were probed with anti-A2BAR antibodies. To control for loading conditions, blots were stripped and reprobed for actin expression. One representative experiment of 3 is shown. (D) To examine the influence of mechanical ventilation on pulmonary A2BAR expression patterns, C57BL/6 mice were ventilated in a pressure-controlled setting over $0 \mathrm{~h}$ or $3 \mathrm{~h}$ (35 mbar inspiratory pressure, 100\% inspired oxygen concentration). Lungs were stained with antibodies for A2BAR. IgG controls were used at identical concentrations and staining conditions as the target primary antibodies (original magnification, $\times 400 ; n=4$ ).
$A 2 B A R$ is induced by mechanical ventilation. To further characterize A2BAR signaling in innate protection during VILI, we next pursued transcriptional consequences of mechanical ventilation on A2BAR expression patterns in vivo. For this purpose, we ventilated mice for 0 to 4 hours using pressure-controlled ventilation (100\% inspired oxygen concentration, inspiratory pressure $35 \mathrm{mbar}$ ). After sacrificing the animals at the time points indicated in Figure 3 , harvesting the lungs, and isolating RNA, we assessed transcript levels of ARs via real-time RT-PCR. Consistent with previous studies showing selective induction of the A2BAR with large-volume ventilation (35), these experiments revealed a prompt and selective induction of the A2BAR (Figure 3A; $P<0.01$ ). In contrast, transcript levels of the A1AR or A3AR were repressed $(P<0.05$; Figure $3 \mathrm{~A}$ ), while A2AAR transcript levels were unchanged with mechanical ventilation (Figure 3A). However, pharmacological studies of survival time or pulmonary albumin leakage with A1AR antagonist (DPCPX, $1 \mathrm{mg} / \mathrm{kg}$ i.p.) or A3AR antagonist (MRS1191, $1 \mathrm{mg} / \mathrm{kg}$ i.p.) revealed no functional changes in A1AR or A3AR inhibition (Supplemental Figure 1; supplemental material available online with this article; doi:10.1172/JCI34203DS1). Consistent with previous studies (36), comparative analysis of pulmonary AR transcript levels at baseline showed that A2BAR had the highest expressional levels (Figure $3 \mathrm{~B}$ ). This distribution was even further magnified following mechanical ventilation, resulting in 5.3-fold higher transcript levels of the A2BAR compared with the A2AAR (Figure 3B). Because a previous study had shown oxygendependent modulation of adenosine-signaling effects (37), we measured relative transcription levels of A2BAR following 4 hours of ventilation at different inspired oxygen concentrations (Supplemental Figure 2). However, we noted no transcriptional effects of the inspired oxygen concentration on A2BAR expression. Therefore, all further experiments were performed at $100 \%$ inspired oxygen concentration. Next we measured A2BAR protein by western blot analysis from whole lungs of ventilated mice and observed ventilation time-dependent increases in A2BAR protein (Figure 3C). Similarly, immunohistochemical staining confirmed A2BAR induction with mechanical ventilation on both pulmonary epithelia and endothelia (Figure 3D), while IgG controls stained negative. Based on studies demonstrating that activation of A2AAR and/or A2BAR is associated with adenylate cyclase-dependent increases in intracellular cAMP (38), leading to increased PKA activity (39), we next studied cAMP levels and PKA activity in pulmonary tissues during mechanical ventilation. As shown in Figure 4, we observed elevations of pulmonary cAMP levels (Figure 4A) and PKA activity (Figure 4B) with mechanical ventilation in WT and $A 2 A A R^{-/-}$ mice. In contrast, mechanical ventilation-associated increases in cAMP/PKA activity were abolished in $A 2 B A R^{-/-}$mice. Consistent with other studies (40), we were able to confirm a protective role of 


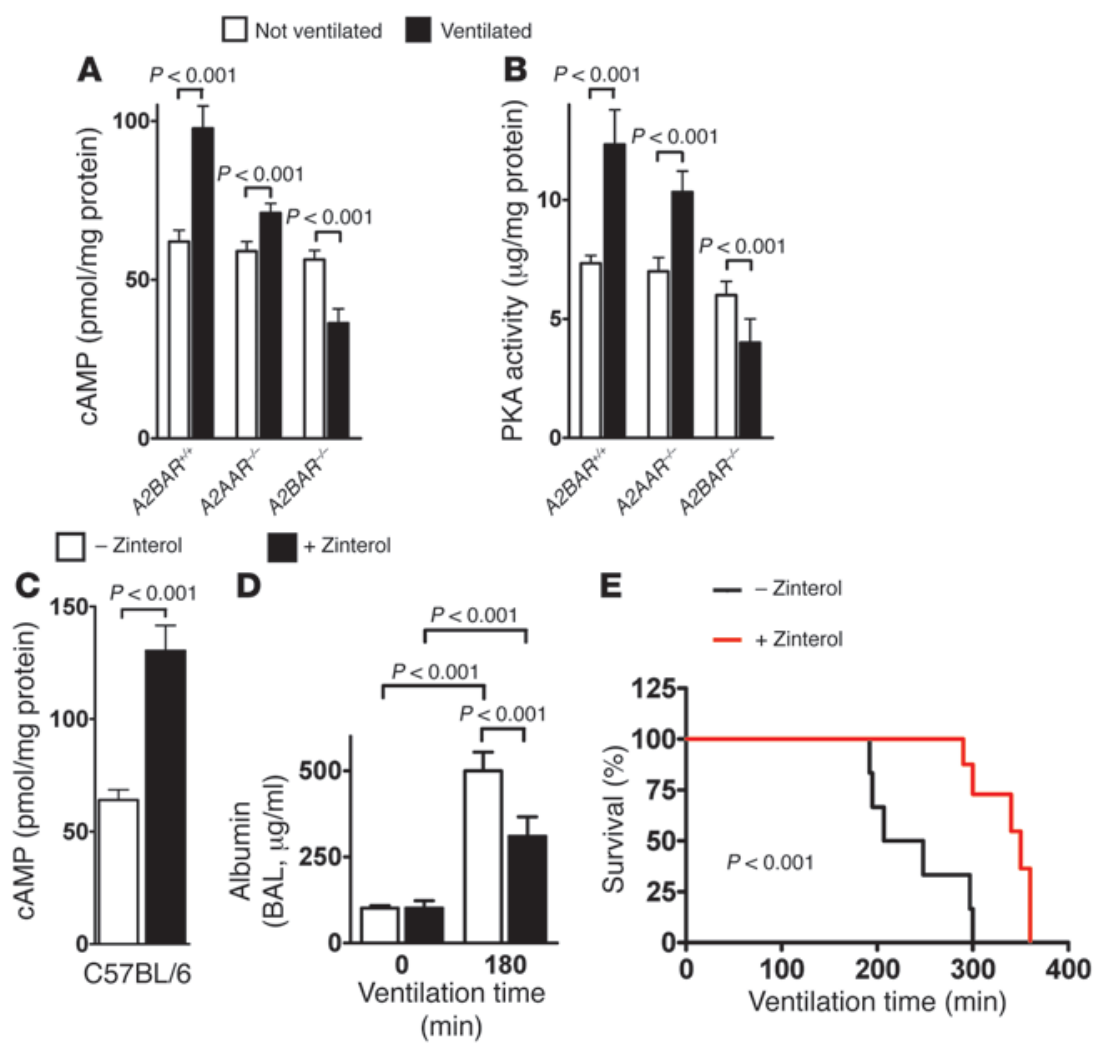

Figure 4

cAMP levels and PKA activity during VILI. (A and B) To assess cAMP levels and PKA activity in pulmonary tissues during $\mathrm{VILI}, A 2 B A R^{-/-}$mice and littermate controls were mechanically ventilated using pressure-controlled ventilation with an inspired oxygen concentration of $100 \%$ over 180 minutes at 45 mbar. Animals were euthanized, and lungs were perfused with $5 \mathrm{ml}$ of PBS through the right ventricle. Lungs were excised, shock-frozen utilizing liquid nitrogen, and mechanically homogenized. cAMP levels (A) and PKA activity (B) were determined by ELISA. Note that the increases in CAMP and PKA activity associated with mechanical ventilation were abolished in $A 2 B A R^{-1-}$ mice. (C) Treatment with the specific $\beta 2$-adrenergic agonist zinterol during VILI. Control C57BL/6 mice were treated with $300 \mu \mathrm{l} 10^{-7} \mathrm{M}$ intratracheal zinterol, and baseline cAMP levels were determined in lung homogenates using a competitive immunoassay kit. (D) Control C57BL/6 mice were treated

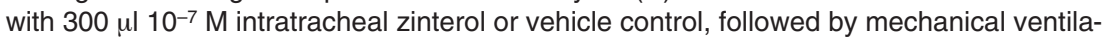
tion using pressure-controlled settings at an inspired oxygen concentration of $100 \%$ and 45 mbar inspiratory pressure for 0 or 180 min. Albumin concentration in the BAL fluid was

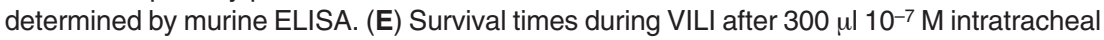
zinterol or vehicle treatment. Mechanical ventilation was applied using pressure-controlled settings (inspiratory pressure of $35 \mathrm{mbar}$, inspired oxygen concentration $100 \%$, respiratory rate and inspiratory/expiratory ratio were adjusted to maintain normal $\mathrm{pH}$ ) until a cardiac standstill was observed in the surface electrocardiogram.

pulmonary cAMP elevation during VILI. In fact, we achieved similar cAMP elevations by intratracheal application of a $\beta 2$-adrenergic agonist (zinterol, $10^{-7} \mathrm{M}, 300 \mu \mathrm{l}$ intratracheally). This treatment was associated with elevated cAMP levels, attenuated albumin leakage, and improved survival (Figure 4, C-E). Taken together, these results suggest that the A2BAR is the predominant pulmonary AR during VILI. As such, A2BAR signaling effects result in elevated pulmonary cAMP levels and attenuation of ALI.

Influence of A2BAR antagonist (PSB1115) and agonist (BAY 60-6583) treatment on VILI. After having shown that the $A 2 B A R^{-/-}$mice developed profound pulmonary inflammation and tissue damage when exposed to VILI, we next sought to confirm these findings using pharmacological approaches. We first studied the highly selective A2BAR inhibitor PSB1115 (10 mg/kg i.p.) (13) during VILI. As shown in Figure 5, A-C, PSB1115 treatment was associated with attenuated survival time in WT and $A 2 A A R^{-/-}$mice, but not in $A 2 B A R^{-/-}$ mice. Moreover, pulmonary albumin leakage and lung inflammation were enhanced following PSB1115 treatment (Figure 5, D-G; $P<0.001)$. At the same time, pulmonary levels of the antiinflammatory cytokine IL-10 were suppressed (Figure 5H; $P<0.001$ ), while pulmonary gas exchange was attenuated (Figure 5I; $P<0.001)$. Next, we treated mice with a previously described highly selective agonist of the A2BAR (BAY 60-6583, $2 \mathrm{mg} / \mathrm{kg}$ i.p.) $(13,16)$. As shown in Figure 6, pretreatment with BAY 60-6583 significantly improved survival and albumin leakage during VILI in WT and $A 2 A A R^{-/-}$mice, but not in $A 2 B A R^{-/-}$mice (Figure 6, A-C; $P<0.001$ ). Similarly, pulmonary inflammation was attenuated, while pulmonary IL-10 levels were increased and gas exchange improved with BAY 60-6583 treatment (Figure 6, D-H; $P<0.001$ ). To extend these studies into a model of endotoxininduced ALI, we next exposed $A 2 B A R^{-/-}$mice and corresponding controls to aerosolized LPS and assessed pulmonary inflammation and albumin leakage into the BAL 24 hours afterward. Similar to our studies in VILI, we found enhanced pulmonary inflammation (Figure 7A) and albumin leakage (Figure 7B) in $A 2 B A R^{-1-}$ mice compared with their controls when exposed to inhaled LPS. Moreover, treatment of WT mice with the selective A2BAR agonist BAY 60-6583 was associated with attenuated pulmonary inflammation (Figure 7C) and albumin leakage into the BAL (Figure 7D) during endotoxin-induced ALI. Taken together, these data show a similar phenotype of the A2BAR in endotoxin-induced ALI and suggest that the A2BAR may be a therapeutic target in ALI induced by mechanical ventilation or LPS inhalation.

VILI in A2BAR bone marrow-chimeric mice. Based on the above results showing expression of the A2BAR on pulmonary tissues, and other studies showing A2BAR on myeloid cells $(15,21)$, we generated A2BAR bone marrow-chimeric mice to study the contribution of pulmonary versus myeloid A2BARs to lung injury during VILI. As expected, $A 2 B A R^{+/+} \rightarrow \mathrm{A}_{2} \mathrm{BAR}^{+/+}$chimeric mice showed a similar degree of VILI-induced increases in ALI as did wild type mice, while $A 2 B A R^{-/-} \rightarrow A 2 B A R^{-/-}$mice showed a similar phenotype as that of $A 2 B A R^{-/-}$mice (Figure 8, A-F). Interestingly, $A 2 B A R^{+/+} \rightarrow A 2 B A R^{-/-}$chimeric mice exhibited VILI-induced albumin leakage and increases in lung water, similar to $A 2 B A R^{-/-}$ mice (Figure 8, A and B). In contrast, $A 2 B A R^{-/-} \rightarrow A 2 B A R^{+/+}$ chimeric mice had attenuated VILI-induced albumin leakage and lung water, very similar to $A 2 B A R^{+/+}$mice (Figure $8 \mathrm{~A}$ ). 

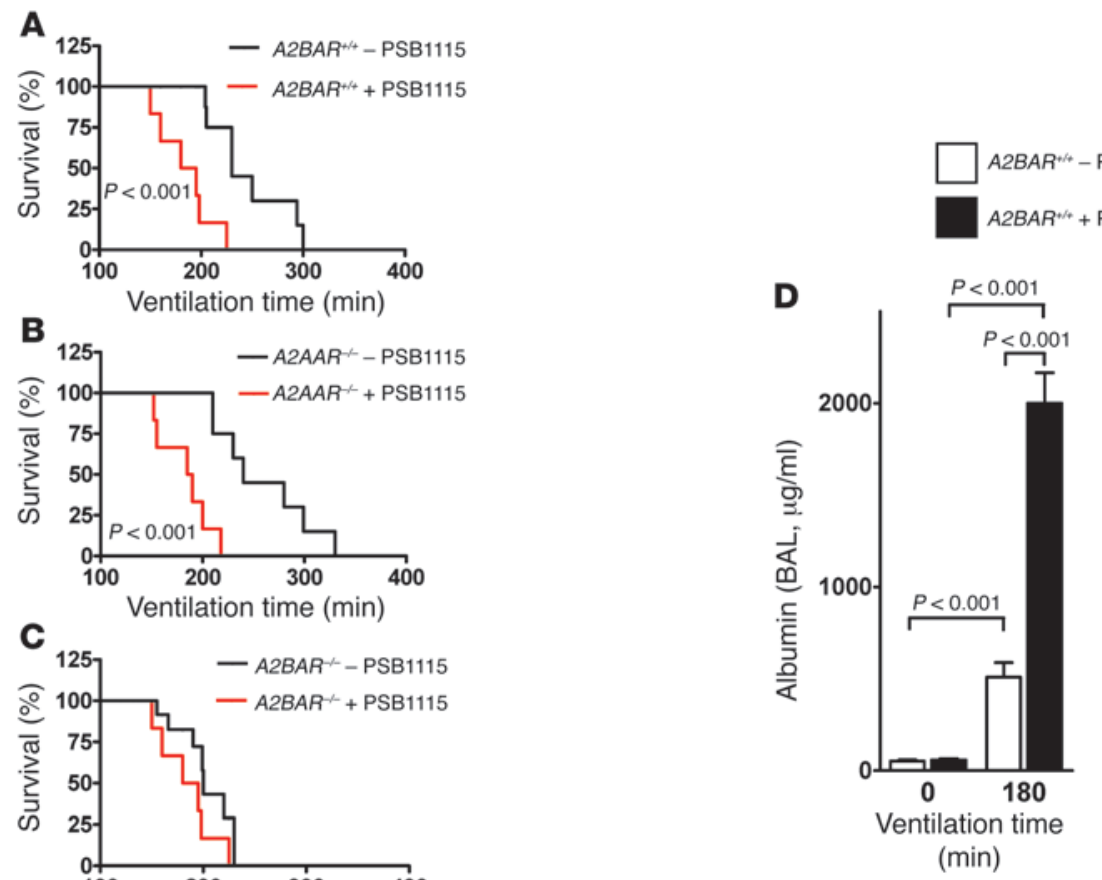

$$
\text { B1115 }
$$$$
\text { B }{ }^{125} \text { - }{ }^{2} \text { - AAR }-P S B 1115
$$

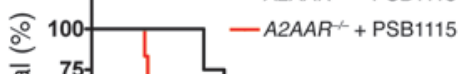

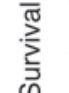
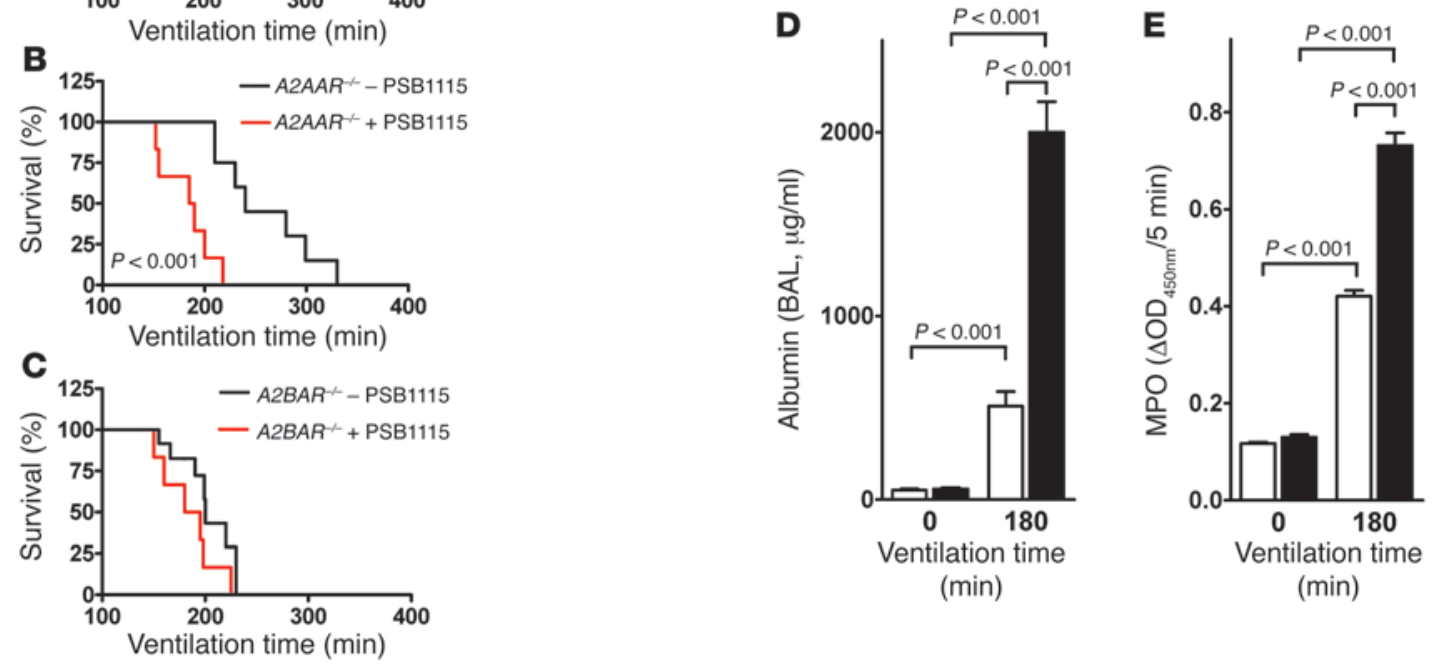

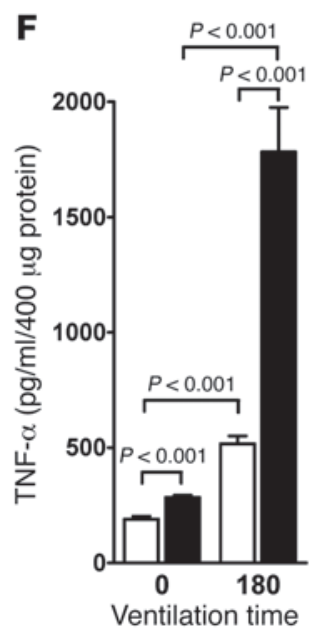

(min)

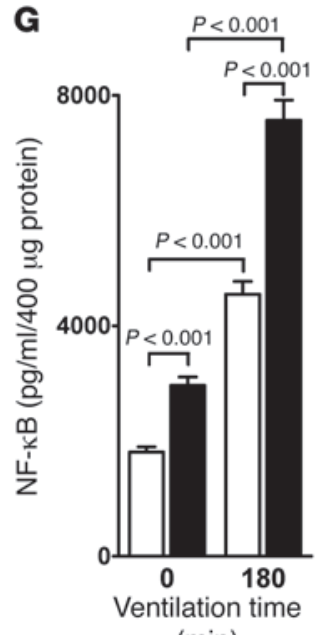

$(\min )$
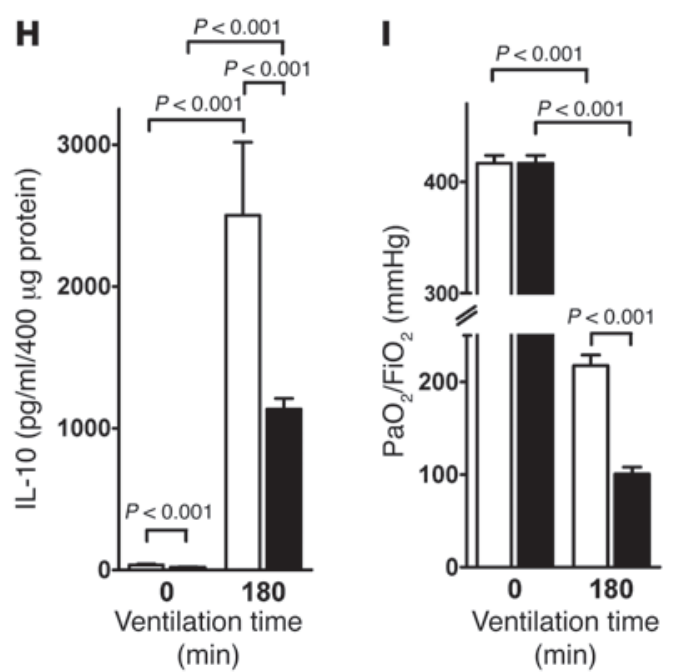

$(\min )$

\section{Figure 5}

A2BAR antagonist treatment PSB1115 during VILI. (A-C), A2BAR ${ }^{+/+}, A 2 A A R^{-/-}$, and $A 2 B A R^{-/-}$mice and their corresponding littermate controls were treated with $10 \mathrm{mg} / \mathrm{kg}$ PSB1115 or vehicle 30 minutes prior to induction of anesthesia. Mechanical ventilation was begun, and mice were ventilated using pressure-controlled settings (inspiratory pressure of $45 \mathrm{mbar}, 100 \%$ inspired oxygen concentration) until a cardiac standstill was observed in the surface electrocardiogram $(P<0.01, n=8)$. (D) Mechanical ventilation was begun, and mice were ventilated for 0 or 180 minutes using pressure-controlled settings (inspiratory pressure of $45 \mathrm{mbar}, 100 \%$ inspired oxygen concentration). Albumin concentration in the BAL fluid was determined by ELISA $(n=6)$. (E) Pulmonary neutrophil sequestration was quantified using a MPO assay. MPO activity was assessed using a spectrophotometric reaction with $O$-dianisidine hydrochloride. Absorbance at $450 \mathrm{~nm}$ was measured and reported as difference in OD over 5 minutes $(n=6)$. (F-H) TNF- $\alpha$, NF- $\mathrm{KB}$, and IL-10 levels were evaluated in lung tissue homogenates using a murine ELISA $(n=6)$. (I) To assess pulmonary gas exchange, blood gas analyses were performed by obtaining arterial blood via cardiac puncture. Analysis was performed immediately, and the ratio of the arterial partial pressure of oxygen to the fraction of inspired oxygen was determined. Results are presented as mean $\pm \operatorname{SD}(n=6)$.

In contrast, inflammatory changes (increased MPO, TNF- $\alpha$, IL-6, and $\mathrm{KC})$ were intermediate in chimeric mice with the genetic deletion of either the myeloid $A 2 B A R\left(A 2 B A R^{-/-} \rightarrow A 2 B A R^{+/}\right)$or the pulmonary A2BAR $\left(A 2 B A R^{+/+} \rightarrow A 2 B A R^{-/-}\right)$, suggesting a com- bination of pulmonary and myeloid A2BAR signaling events in attenuating lung inflammation during VILI. Taken together, these studies suggest a dual role of the A2BAR during VILI in which pulmonary A2BARs mainly attenuate pulmonary edema 
A

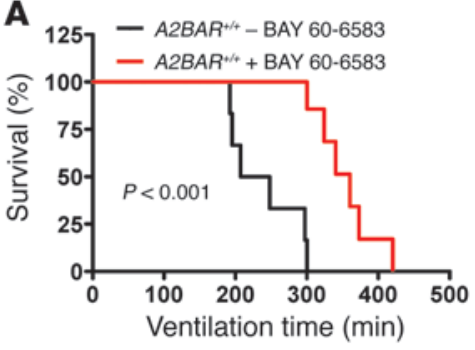

B
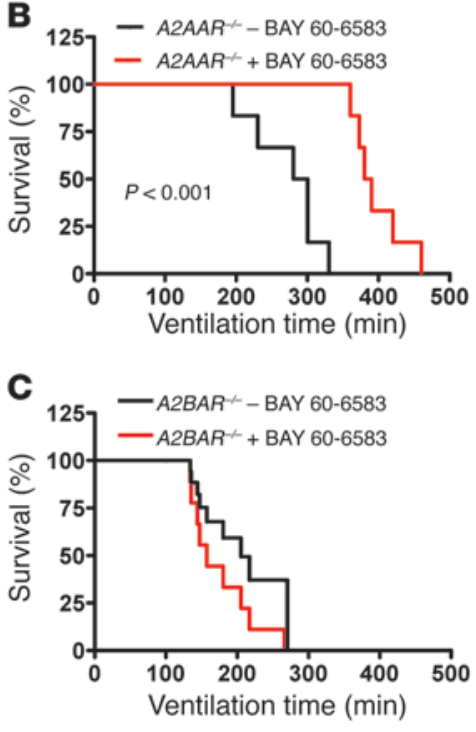

$\square{ }^{A 2 B A R^{+/+}-\text {BAY } 60-6583}$
A2BAR $^{* /+}+$ BAY $60-6583$

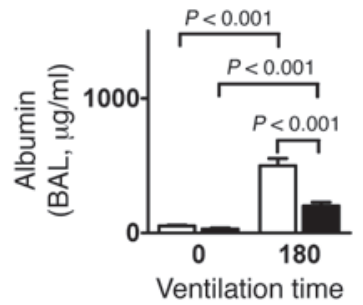

(min)
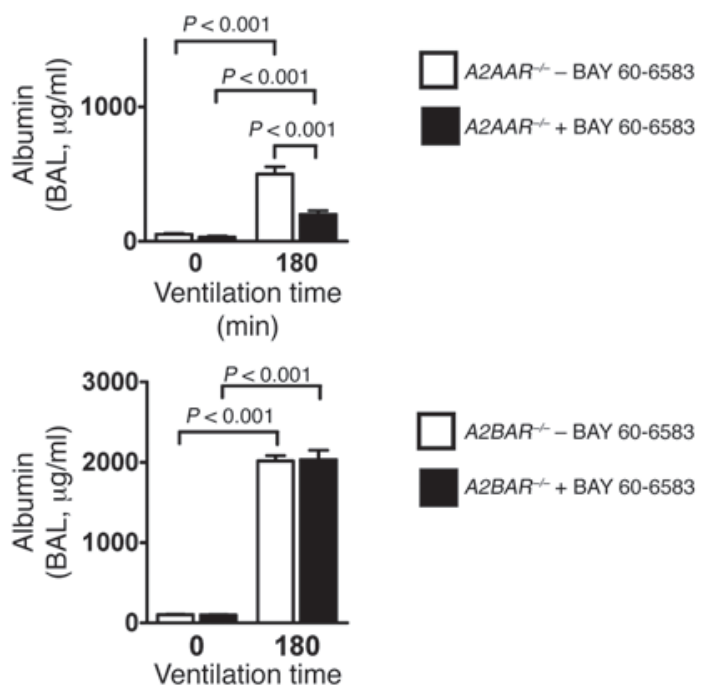

$\square$ A2BAR $^{-1}-$ BAY 60-6583

A2BAR + BAY 60-6583

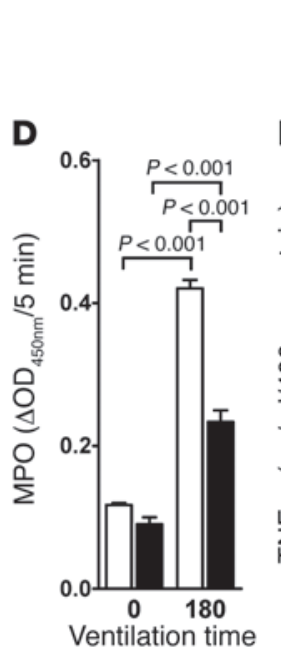

(min)

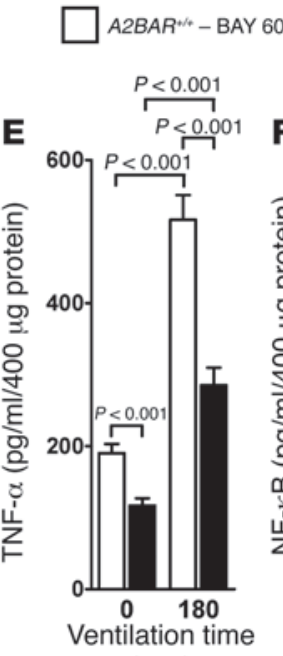

(min)

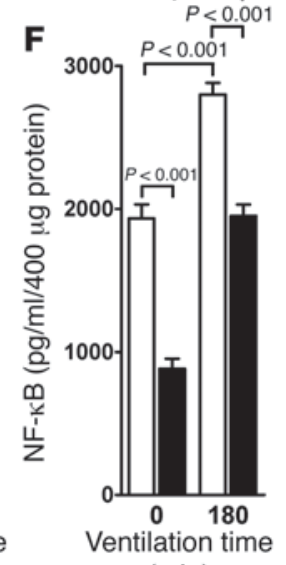

(min)

(min)

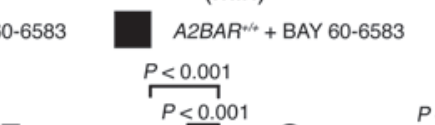

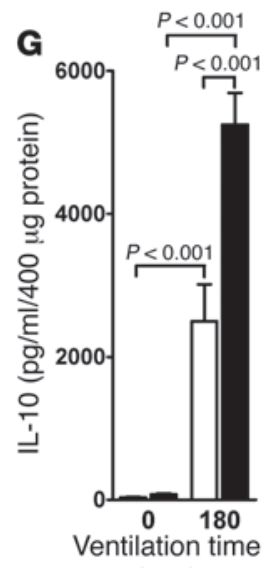

(min)

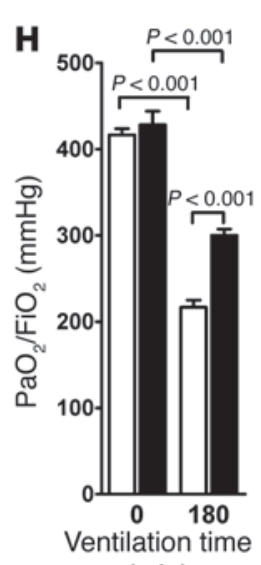

(min)
Figure 6

A2BAR agonist (BAY 606583) treatment. (A-C) $A 2 B A R^{+/+}, A 2 A A R^{-/-}$, and $A 2 B A R^{-/-}$mice and their corresponding littermate controls were treated with $2 \mathrm{mg} / \mathrm{kg}$ BAY 60-6583 or vehicle 30 minutes prior to induction of anesthesia. Mechanical ventilation was begun, and mice were ventilated using pressurecontrolled settings (inspiratory pressure of $45 \mathrm{mbar}, 100 \%$ inspired oxygen concentration) until a cardiac standstill was observed in the surface electrocardiogram $(P<0.01$, $n=8$ ). In other studies, albumin concentrations in the $B A L$ fluid were determined by ELISA after mechanical ventilation using pressurecontrolled settings with an inspired oxygen concentration of $100 \%$ for 180 minutes at 45 mbar. (D) Pulmonary neutrophil sequestration was quantified using a MPO assay $(n=6)$. (E-G) TNF- $\alpha$, $N F-\kappa B$, and IL-10 levels were evaluated in lung tissue homogenates using murine ELISA $(n=6)$. (H) To assess pulmonary gas exchange, blood gas analyses were performed by obtaining arterial blood via cardiac puncture. The ratio of the arterial partial pressure of oxygen to the fraction of inspired oxygen was determined. Results are presented as mean $\pm \operatorname{SD}(n=6)$. and albumin leakage, while neutrophil accumulation and release of proinflammatory mediators are affected by both pulmonary and myeloid A2BARs.

Barrier protection of $B A Y$ 60-6583 requires pulmonary $A 2 B A R$, while antiinflammatory effects involve pulmonary and myeloid A2BARs. To further study the contribution of pulmonary and hematopoietic A2BARs to VILI, we next exposed A2BAR bone marrow-chimeric mice pretreated with BAY 60-6583 to VILI. Bone marrow-chimeric A2BAR mice expressing the A2BAR on tissues but not on their hematopoietic cells $\left(A 2 B A R^{-/-} \rightarrow A 2 B A R^{+++}\right.$mice $)$showed reduced
BAL albumin leakage and lower wet/dry ratios when treated with BAY 60-6583 (2 mg/kg i.p.) compared with their vehicle-treated counterparts. In contrast, BAY 60-6583 treatment had no effect on albumin leakage or wet/dry ratios in $A 2 B A R^{+/+} \rightarrow A 2 B A R^{-/-}$or $A 2 B A R^{-/-} \rightarrow A 2 B A R^{-/-}$chimeric mice, suggesting that pulmonary A2BARs play a role in dampening pulmonary edema during VILI (Figure 9, A and B). In contrast, pulmonary inflammation (as assessed by pulmonary TNF- $\alpha$ and MPO levels) was attenuated with BAY 60-6583 pretreatment in both $A 2 B A R^{+++} \rightarrow A 2 B A R^{-/-}$and $A 2 B A R^{-/-} \rightarrow A 2 B A R^{+/+}$mice, suggesting a combination of pulmo- 

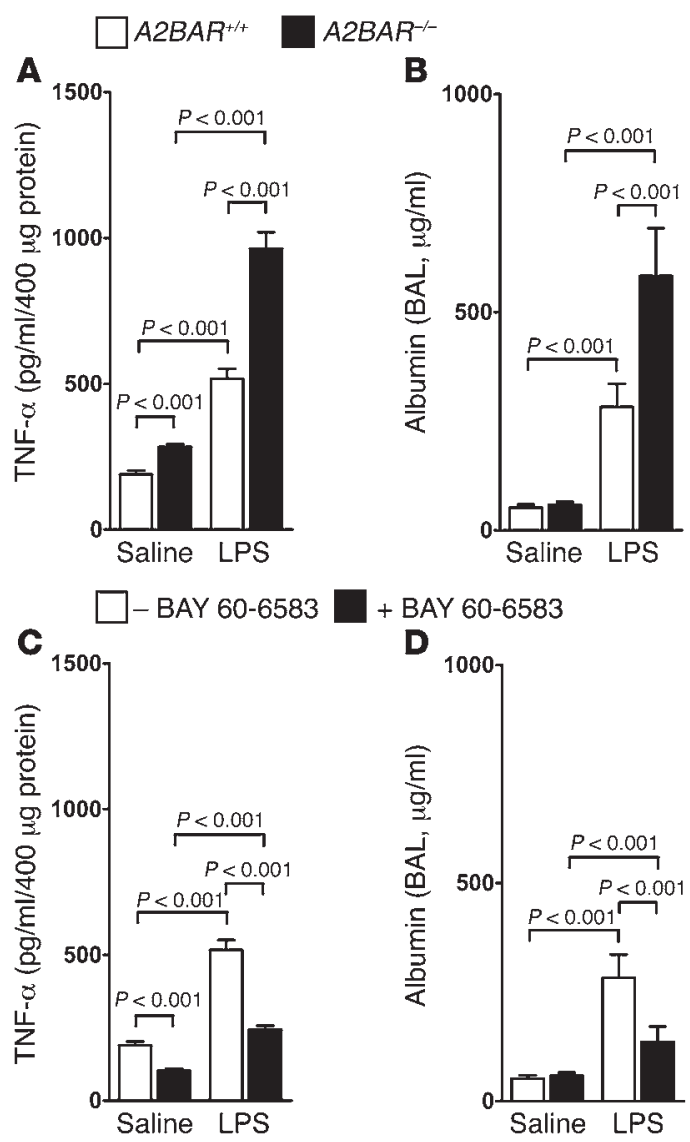

nary and hematopoietic A2BARs in attenuating lung inflammation during VILI (Figure 9, C and D). Taken together, these data suggest that signaling through pulmonary A2BARs is critical for attenuating VILI-associated increases in pulmonary edema, while myeloid and pulmonary A2BAR signaling attenuates lung inflammation induced by VILI.

A2BAR signaling enhances amiloride-sensitive fluid transport during VILI. Based on previous studies showing a critical role of extracellular adenosine signaling in maintaining proper fluid levels in the lung alveoli (41-43) and our observation of increased pulmonary edema during VILI with genetic deletion or pharmacological inhibition of the A2BAR, we pursued the hypothesis that A2BAR signaling enhances AFC during VILI. For this purpose, we measured $\mathrm{AFC}$ in $A 2 B A R^{-/-}$mice and littermate controls (Figure $10 A)$ during VILI. While AFC was enhanced with VILI, AFC was significantly attenuated in $A 2 B A R^{-/}$mice. Intraalveolar treatment with the epithelial sodium channel $(\mathrm{ENaC})$ inhibitor amiloride revealed that increases in AFC with VILI involve $\mathrm{ENaC}$-dependent fluid transport. In addition, differences in AFC between $A 2 B A R^{-/-}$ and $A 2 B A R^{+/+}$mice were attenuated following amiloride treatment, suggesting that A2BAR signaling contributes to ENaCdependent fluid transport. As shown in Figure 10B, intraalveolar treatment of WT mice with the A2BAR antagonist PSB1115 attenuated AFC, resulting in a similar phenotype to that observed in $A 2 B A R^{-1-}$ mice. Studies in A2BAR bone marrow-chimeric mice revealed that mice with pulmonary deletion of the A2BAR had attenuated AFC during VILI, while deletion of the myeloid A2BAR had little effect on AFC (Figure 10C). Moreover, treat-

\section{Figure 7}

A2BAR signaling during LPS-induced lung injury. (A and B) $A 2 B A R^{-1-}$ and $A 2 B A R^{+/+}$mice were exposed to LPS inhalation for 30 minutes. Twenty-four hours after LPS exposure, TNF- $\alpha$ in lung tissue homogenates and albumin concentration in the BAL fluid were determined using a murine ELISA $(n=6)$. (C and D) $A 2 B A R^{+/+}$mice received $2 \mathrm{mg} / \mathrm{kg}$ BAY 60-6583 i.p. or were treated with vehicle 30 minutes prior to LPS inhalation. (C) TNF- $\alpha$ levels in lung tissues and (D) albumin concentrations in the BAL fluid $(n=6)$.

ment of WT mice with the A2BAR-specific agonist BAY 60-6583 increased AFC (Figure 10D) and survival time during VILI (Figure $10, \mathrm{E}$ and $\mathrm{F}$ ). However, increases in $\mathrm{AFC}$ or survival with $\mathrm{BAY}$ 60-6583 were abolished when given together with amiloride (Figure $10, \mathrm{D}-\mathrm{F})$, suggesting that A2BAR signaling enhances ENaCdependent fluid transport. Additional studies with a specific inhibitor of the CFTR $\left(\right.$ CFTR $_{\text {inh- } 172}, 10^{-6} \mathrm{M}, 300 \mu \mathrm{l}$ intratracheally) (41) showed no influence on AFC during VILI (Supplemental Figure 3). These findings are consistent with studies showing no changes in AFC in gene-targeted mice for the CFTR (44) and with studies using selective CFTR inhibitors $\left(\mathrm{CFTR}_{\text {inh-172 }}, 1 \mu \mathrm{M}\right)(41)$.

Based on previous studies showing that elevated endogenous epinephrine can markedly upregulate AFC under pathological conditions such as sepsis or pneumonia $(45,46)$, we studied plasma epinephrine levels during VILI. Consistent with these studies $(45,46)$, plasma epinephrine levels were elevated during VILI (Figure 11A). However, no differences between $A 2 B A R^{-/-}$mice or their corresponding control mice were observed, suggesting that A2BAR signaling is not involved in VILI-associated increases in plasma epinephrine (Figure 11B). Similarly, increases in AFC with BAY 60-6583 treatment were not blocked by pretreatment with propanolol, a nonselective $\beta$-adrenergic receptor antagonist (Figure $11 \mathrm{C}$ ). However, as shown earlier, treatment with the $\beta 2$-adrenergic agonist zinterol $\left(10^{-7} \mathrm{M}, 300 \mu \mathrm{l}\right.$ intratracheally) was associated with elevated cAMP levels, attenuated albumin leakage, and improved survival (Figure 4, C-E). Simultaneous treatment with zinterol and BAY 60-6583 were associated with increased elevations of CAMP and enhancement of AFC. In fact, ANOVA testing followed by Bonferroni correction revealed a statistically significant increase with the combination of zinterol and BAY 60-6583 (mice treated with zinterol alone had an AFC of 58.56\% following high-pressure ventilation; mice treated with zinterol and BAY $60-6583$ had an AFC of $64.3 \% ; P<0.01$ ). While statistical analysis of these data determined that the groups were different, these differences were very small and may not be biologically significant (Figure 11D). Thus, segregation of the 2 pathways is complicated. The stimulation of A2BAR increases cAMP and PKA, as does $\beta$-agonist stimulation. While adenosine signaling resulted in $G$ s protein-coupled and cAMP-elevating A2BAR activation, $\beta 2$-adrenergic agonist stimulation converged on a similar signaling cascade, thereby resulting in enhancement of AFC. Taken together, these studies provide evidence for a role of A2BAR in counterbalancing increases in pulmonary edema during VILI via activation of amiloride-sensitive fluid transport mechanisms.

\section{Discussion}

ALI contributes substantially to critical illness, as it occurs frequently (2) and carries a high mortality rate (1). Moreover, the only therapeutic interventions currently available are elimination of the causative agents and supportive therapy (1). Never- 

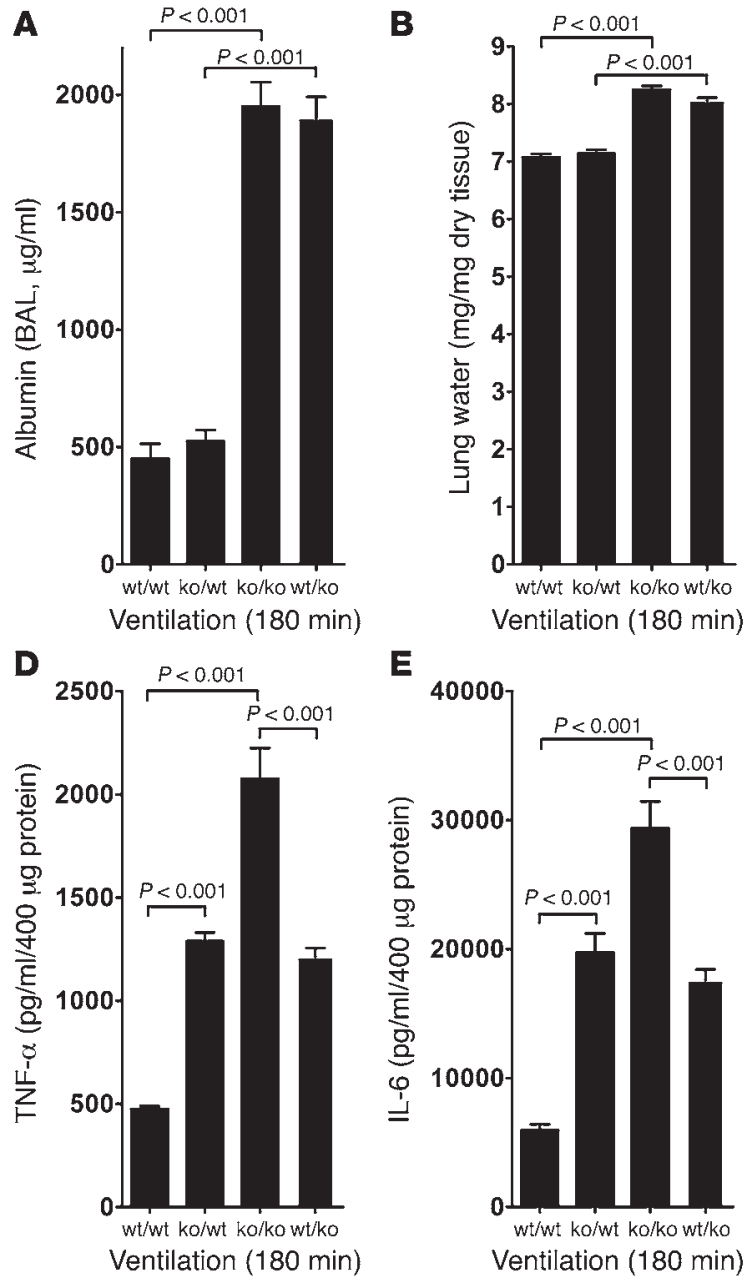

B

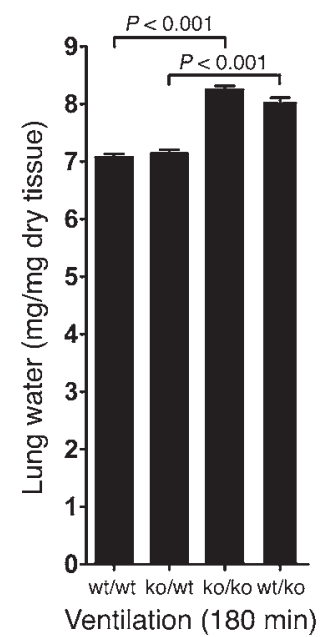

$\mathbf{F}$

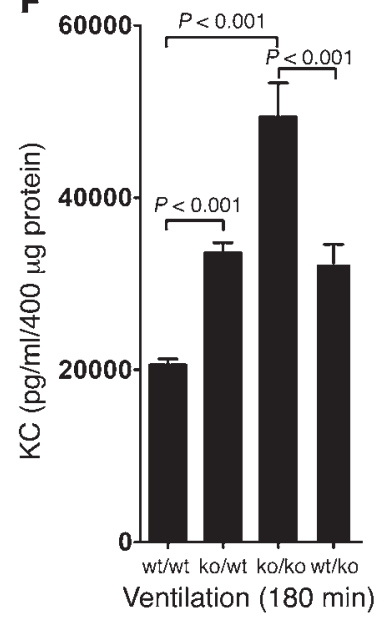

Figure 8

VILI in A2BAR bone marrow-chimeric mice. A2BAR bone marrow-chimeric mice were subjected to VILI using mechanical ventilation for 180 minutes at an inspiratory pressure of $45 \mathrm{mbar}$ and $100 \%$ inspired oxygen concentration. (A) Albumin concentration in the BAL fluid was determined by ELISA. $\mathrm{WT} / \mathrm{WT}, A 2 B A R^{+/+} / A 2 B A R^{+/+} ; \mathrm{KO} / \mathrm{WT}$, $A 2 B A R^{-1-} A 2 B A R^{+/+} ; \mathrm{KO} / \mathrm{KO}, A 2 B A R^{-1-l}$ A2BAR $R^{-/-}$; WT/KO, A2BAR $R^{+/+} / A 2 B A R^{-/-}$. (B) Following ventilation at the indicated settings, lungs were excised en bloc and weighed. Lungs were lyophilized for 48 hours, and lung water content (mg lung water/mg dry tissue) was determined. Note the increased albumin concentration and lung water content in A2BAR $R^{-/ /} / A 2 B A R^{-/-}$and $A 2 B A R^{+/+} / A 2 B A R^{-/-}$ mice compared with $A 2 B A R^{+/+} / A 2 B A R^{+/+}$ mice $(P<0.001)$. (C) Pulmonary neutrophil sequestration was quantified using a MPO assay. MPO activity was assessed using a spectrophotometric reaction with $O$-dianisidine hydrochloride. Absorbance at $450 \mathrm{~nm}$ was measured and reported as difference in OD over 5 minutes. (D-F) TNF- $\alpha$, IL-6, and $\mathrm{KC}$ levels were evaluated in lung tissue homogenates using a mouse ELISA. Note the similar degree of pulmonary inflammation in $A 2 B A R^{-/-} / A 2 B A R^{+/+}$and $A 2 B A R^{+/+/}$ $A 2 B A R^{-/-}$mice compared with $A 2 B A R^{++/}$ A2BAR+/+ mice. $n=6$. theless, in many instances, ALI resolves spontaneously through unknown mechanisms. Here, we used VILI as a model for ALI to study the role of extracellular adenosine signaling pathways in endogenous lung protection. Our results point toward a pivotal role of the A2BAR in attenuating VILI-induced increases in pulmonary edema and inflammation. Moreover, our in vivo studies of A2BAR bone marrow-chimeric mice suggest an important contribution in attenuating lung injury by pulmonary A2BARs by maintaining the capillary-alveolar barrier during VILI. In addition, studies of alveolar fluid transport suggest that A2BAR signaling attenuates pulmonary edema formation by enhancing amiloride-sensitive fluid transport mechanisms. These findings correlate with elevations of plasma epinephrine levels and elevations of cAMP, roughly equivalent to the effects of stimulation with a $\beta 2$-adrenergic agonist. Taken together, these findings identify a surprising role for pulmonary A2BAR signaling in attenuating ALI induced by mechanical ventilation or LPS exposure, suggesting that the A2BAR protects the lungs by attenuating acute inflammation and increasing AFC.

The present studies are consistent with previous work on extracellular adenosine signaling in alveolar fluid transport (41, 42). In fact, recent studies demonstrate that adenosine helps maintain proper fluid levels in the lung alveoli, and such findings have implications for treatment of fluid buildup in the lung (42). In an elegant study, Factor et al. (41) showed that levels of extracellular adenosine regulate the activities of 2 ion channels, the $\mathrm{ENaC}$ and the chloride channel CFTR. Adenosine regulation of the activities of these 2 channels establishes the balance between fluid secretion into the alveolus and fluid absorption from it. Under conditions of alveolar filling - such as occurs during pulmonary edema or VILI - adenosine concentrations may decrease, resulting in loss of A1AR-mediated pathways and activation of A2AAR-mediated pathways $(41,42)$. A2AAR-mediated pathways increase ENaC activity, increasing sodium absorption from the alveolus. Chloride follows sodium out of the cell to maintain electroneutrality, and, as a result of this sodium and chloride flux, fluid leaves the alveolus (i.e., AFC increases) $(41,42)$. It is important to point out that during large-volume ventilation, the A2BAR is transcriptionally induced (an almost 10-fold induction was observed in the present study, consistent with previous studies of nucleoside receptors during large-volume ventilation; ref. 35) and becomes the predominant AR in the lungs. Such findings may explain our results for the role of A2BAR signaling in activation of AFC during VILI. While A2AAR and A2BAR signaling pathways both converge to increase pulmonary cAMP levels (43), a combined agonist of the A2AAR and A2BAR may represent the most effective pharmacological approach to utilizing adenosine pathways to dry out the lungs during pulmonary edema or VILI. 

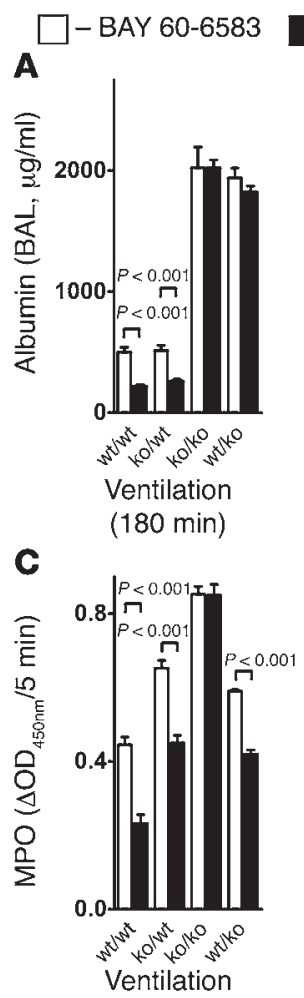

(180 min)
+ BAY 60-6583
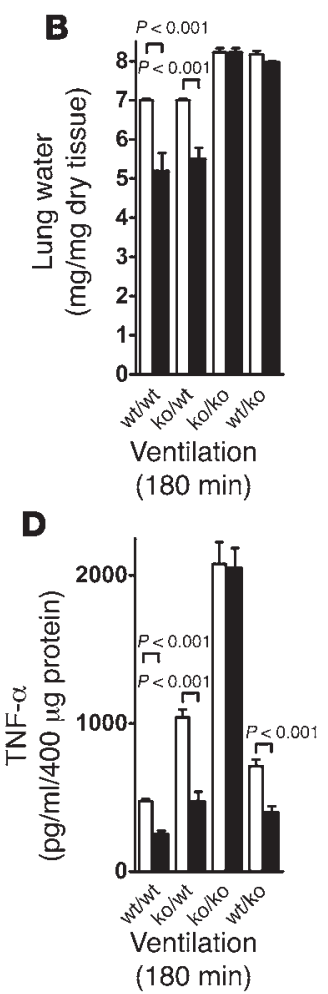

The observation of increased capillary-alveolar leakage with targeting of the A2BAR during VILI suggests a protective role of extracellular adenosine signaling for maintaining the pulmonary barrier function. This is consistent with previous studies showing barrier protection and antiinflammatory effects of extracellular adenosine signaling in models of acute injury (47), inflammation (21), and hypoxia $(11,48)$. Previous studies found different ARs responsible for tissue protection under such conditions (11-13, 16). For example, an elegant study in mice deficient in the $A 2 A A R$ showed increased inflammation-associated tissue damage (18), providing evidence for A2AAR signaling as a mechanism for regulating acute inflammatory responses in vivo. In this study, a subthreshold dose of an inflammatory stimulus was associated with minimal tissue damage in control animals. A similar stimulus was sufficient to induce extensive tissue damage, more prolonged and higher levels of pro-inflammatory cytokines, and death in $A 2 A A R^{-1-}$ mice. Similar observations were made using other models of inflammation, liver damage, or bacterial endotoxin-induced septic shock, suggesting a role for A2AAR in the limitation and termination of tissue-specific and systemic inflammatory responses (18). Other studies of LPS-induced ALI confirmed a critical role for signaling through A2AARs in attenuating LPS-induced lung inflammation $(4,37)$. As such, another study revealed that hypoxia increased adenosine signaling, the effects of which are protective during LPS-induced lung injury (37). In fact, the administration of high oxygen concentration further aggravated lung injury in that study. The authors found that this was due to inhibition of hypoxia-elicited lung protective mechanisms (37). Along the same lines, a recent study has suggested a role for hematopoietic A2AAR signaling in attenuating LPS-induced lung injury (4). Consistent with the present work, in vitro studies have indicated a critical role

\section{Figure 9}

BAY 60-6583-dependent lung protection during VILI in A2BAR bone marrow-chimeric mice. (A-D) A2BAR bone marrow-chimeric mice were treated with BAY $60-6583(2 \mathrm{mg} / \mathrm{kg}) 30$ minutes prior to induction of anesthesia. Mechanical ventilation was begun, and mice were ventilated using an inspiratory pressure of $45 \mathrm{mbar}, 100 \%$ inspired oxygen concentration, for 180 minutes. Results are presented as mean \pm SD. $n=6$. (A) Albumin concentration in the BAL fluid was determined by ELISA. (B) Following mechanical ventilation, lungs were excised en bloc and weighed. Lungs were then lyophilized for 48 hours, and lung water content (mg lung water/mg dry tissue) was determined. Capillaryalveolar barrier protection was observed only in $A 2 B A R^{+/ /} / A 2 B A R^{+/+}$

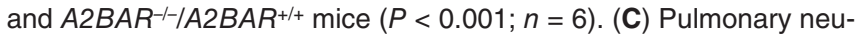
trophil sequestration was quantified using a MPO assay. MPO activity was assessed using a spectrophotometric reaction with $O$-dianisidine hydrochloride. Absorbance at $450 \mathrm{~nm}$ was measured and reported as difference in OD over 5 minutes. (D) TNF- $\alpha$ levels were evaluated in lung tissue homogenates using a mouse ELISA. Note the similar levels of pulmonary inflammation in $A 2 B A R^{-/-} / A 2 B A R^{+/+}$and $A 2 B A R^{+/+}$ $A 2 B A R^{-1-}$ mice.

of signaling through the A2BAR in the re-sealing of endothelia during transendothelial migration of neutrophils (49), particularly during conditions of limited oxygen availability $(14,15,27$, 50). Moreover, pharmacological inhibition or genetic deletion of the A2BAR during hypoxia exposure is associated with increased pulmonary edema and vascular leakage $(11,51)$. Interestingly, another study suggested protective roles of HIF activators in respiratory distress syndrome and bronchopulmonary dysplasia (52). Serendipitously, the pacemaker enzyme of extracellular adenosine generation, CD73 (53), and the A2BAR (54) are both selectively induced by HIF- 1 and were both shown to be central to innate lung protection during VILI (10). The seemingly contradictory findings that the A2AAR appears to be critical to mediating LPS-induced lung injury $(18,37)$ but that the A2BAR plays a pivotal role in VILI might be explained by differences between LPS- and VILI-induced ALIs and in AR expression patterns during such conditions.

The present studies in bone marrow-chimeric mice suggest that mice genetically targeted for myeloid A2BARs exhibit no significant increase in albumin leak or lung water. On the other hand, the mice had a significant degree of pulmonary inflammation (Figure 8), as determined by increased levels of cytokines and MPO. These data indicate that increased levels of cytokines or neutrophils do not contribute to lung injury. This is consistent with previous studies showing that neutropenia does not prevent significant injury to the alveolar epithelium during ALI induced by hypoxia $(55,56)$. Studies of ambient hypoxia exposure ( $8 \%$ oxygen over 4 hours) of A2BAR bone marrow-chimeric mice revealed that hypoxia-associated vascular leakage was attenuated by vascular A2BAR signaling effects (11). In contrast, hypoxia-associated inflammation mainly involved myeloid A2BAR signaling (11).

In contrast to the present study of acute injury, studies investigating chronic pulmonary disease have identified a potential detrimental role of elevated adenosine levels (57-63). For example, levels of adenosine are chronically increased in the lungs of asthmatics (61) and correlate with the degree of inflammatory insult (62), suggesting a provocative role of adenosine in asthma or chronic obstructive pulmonary disease (63). In addition, adenosine deaminase-deficient (ADA-deficient) mice develop signs of chronic pulmonary injury in association with chronically elevated pulmonary adenosine levels. In fact, ADA-deficient 
A

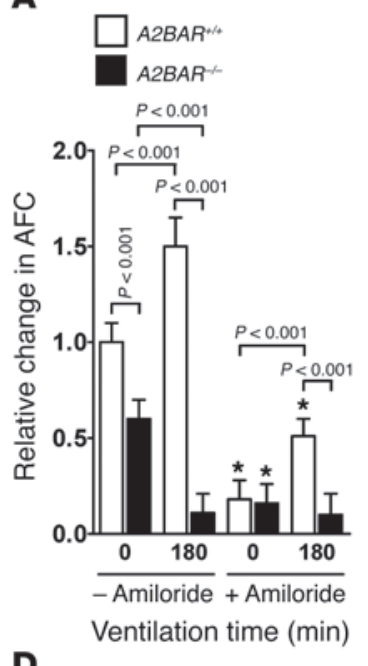

D

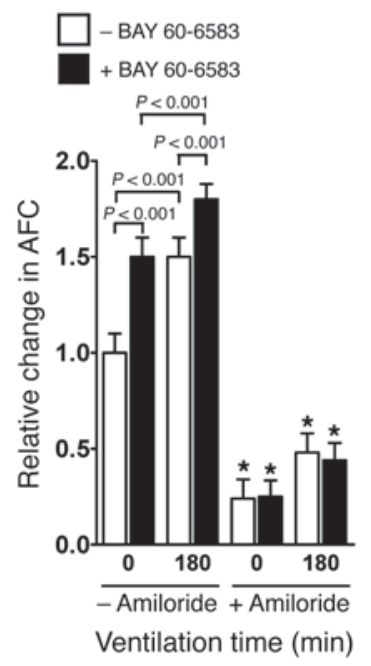

B
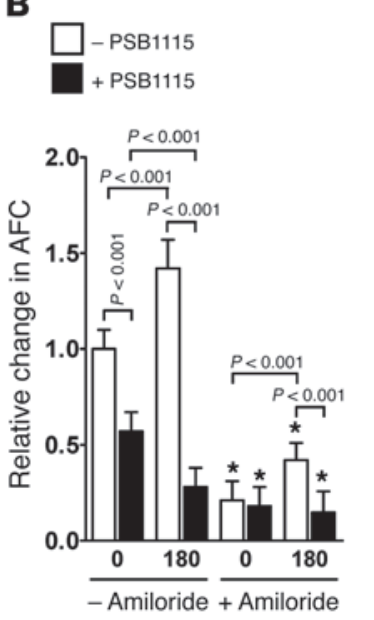

Ventilation time (min)

E
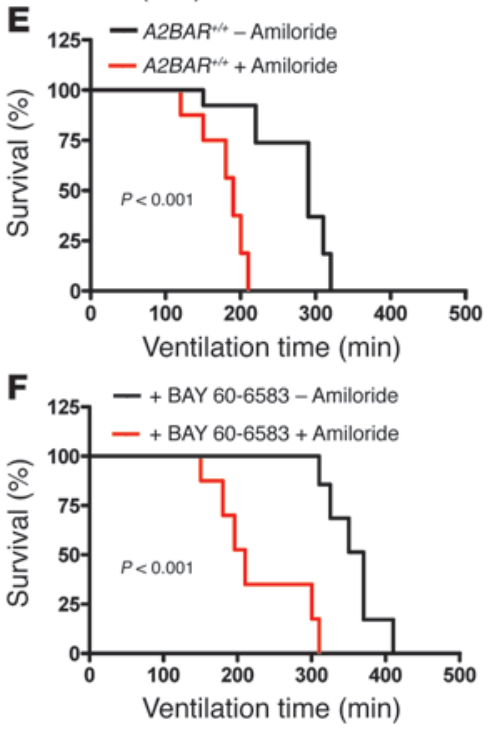

Figure 10

Contribution of A2BAR signaling to AFC during VILI. (A) To determine whether A2BAR signaling affects pulmonary fluid transport, we measured AFC using a mechanically ventilated live mouse model. $A 2 B A R^{-1-}$ mice and littermate controls were mechanically ventilated in a pressure-controlled setting at 45 mbar for 0 to 180 minutes. AFC was measured by instilling $300 \mu$ l of iso-osmolar $0.9 \%$ $\mathrm{NaCl}$ solution with $5 \%$ BSA. Mechanical ventilation was continued for 30 minutes, and AFC was measured in the presence or absence of the ENaC inhibitor amiloride $(1 \mathrm{mM})$. ${ }^{*} P<0.01$ compared with no amiloride. $n=8$. (B) Influence of A2BAR antagonist PSB1115 on AFC during VILI. Following induction of VILI, control mice received PSB1115 $(1 \mu \mathrm{M})$ alone or in combination with amiloride ( $1 \mathrm{mM}$ ), and AFC was determined. ${ }^{*} P<0.01$ compared with no amiloride. $n=8$. (C) VILI was induced in A2BAR bone marrow-chimeric mice, and AFC was determined. ${ }^{*} P<0.001$ compared with $A 2 B A R^{+/+} / A 2 B A R^{+/+} . n=8$. (D) Influence of A2BAR agonist BAY 60-6583 on AFC during VILI. Following induction of VILI, control mice received BAY 60-6583 $(1 \mu \mathrm{M})$ alone or in combination with amiloride $(1 \mathrm{mM})$, and AFC was determined ${ }^{*} P<0.01$ compared with no amiloride. $n=8$. (E and F) Control mice were treated with intratracheal BAY 60-6583 $(1 \mu \mathrm{M}, 100 \mu \mathrm{l})$ and/or amiloride $(1 \mathrm{mM})$ or vehicle following tracheotomy and initiation of mechanical ventilation. Mice were ventilated using pressure-controlled settings (inspiratory pressure of $45 \mathrm{mbar}, 100 \%$ inspired oxygen concentration) until a cardiac standstill was observed in the surface electrocardiogram. Note that the longer survival time during VILI with A2BAR agonist treatment was abolished following amiloride treatment $(n=8)$.

mice die within weeks after birth from severe respiratory distress (64), and studies have suggested that attenuation of adenosine signaling may reverse the severe pulmonary phenotypes in ADAdeficient mice, suggesting that chronic adenosine elevation can
(The Jackson Laboratory) for over 12 generations to generate congenic C57BL/6N strain A2BAR mutant mice. Heterozygotes were then intercrossed to generate WT, heterozygous, and homozygous mutant progeny. Characterization and validation was performed by Deltagen and in our laboratory in Tübingen as described previously 

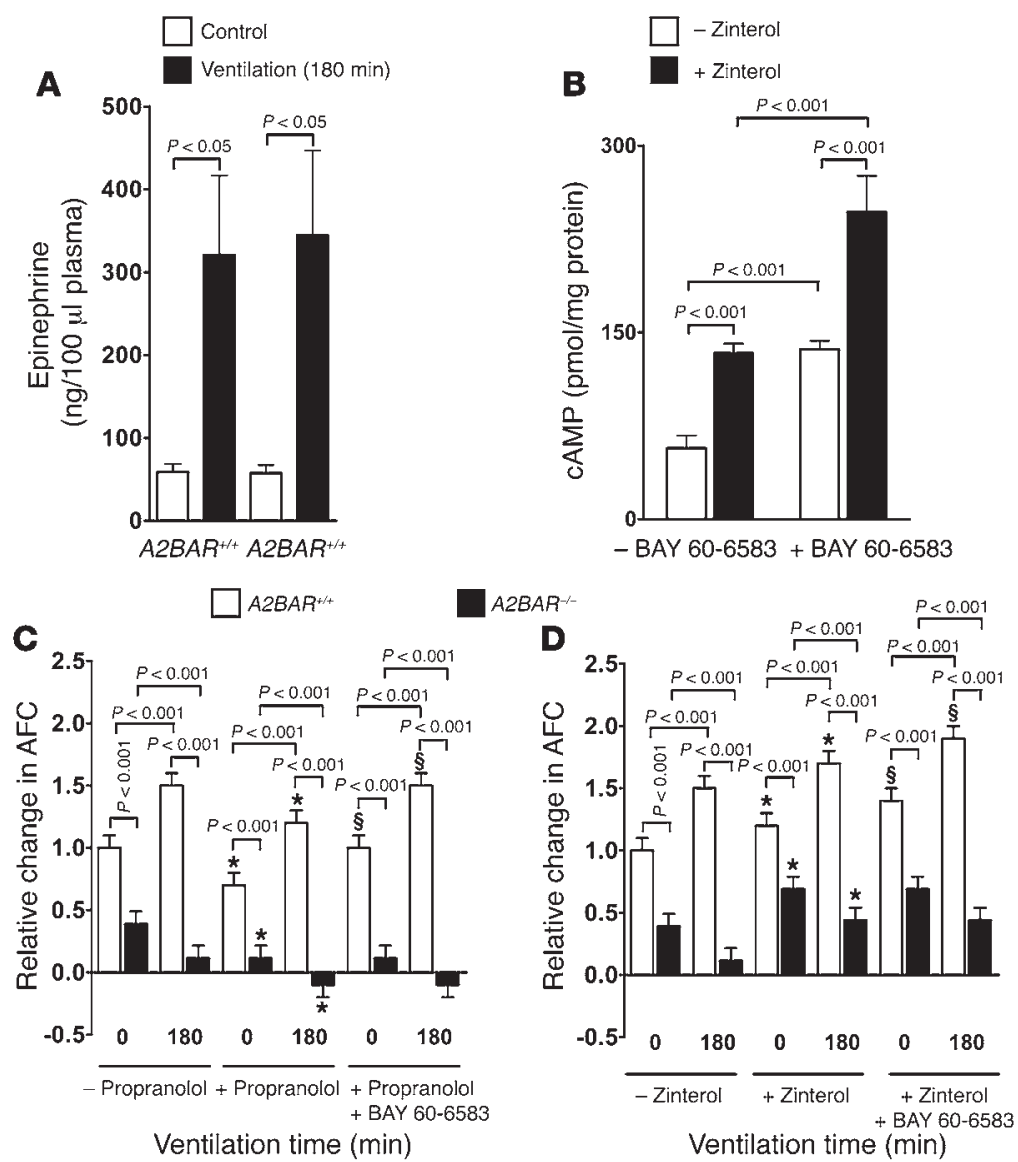

\section{Figure 11}

Influence of $\beta 2$-adrenergic and/or A2BAR signaling on AFC during VILI. (A) Epinephrine plasma levels in $A 2 B A R^{-1-}$ and $\mathrm{A}_{2} \mathrm{BAR}^{+/+}$mice that were mechanically ventilated in a pressure-controlled setting at $45 \mathrm{mbar}$ over 180 minutes. (B) Basal cAMP levels in lung tissue from $A 2 B A R^{+/+}$mice that were treated with zinterol and/or BAY 60-6583. (C and D) To determine $\beta 2$-adrenergic and $A 2 B A R$ signaling effects on pulmonary fluid transport, $A 2 B A R^{-/-}$and $A 2 B A R^{+/+}$mice were mechanically ventilated in a pressure-controlled setting at $45 \mathrm{mbar}$ for 0 to 180 minutes. AFC was measured by instilling $300 \mu \mathrm{l}$ of iso-osmolar $0.9 \% \mathrm{NaCl}$ solution with $5 \% \mathrm{BSA}$. Mechanical ventilation was continued for 30 minutes, and AFC was measured in the presence or absence of the nonselective $\beta$-adrenergic receptor antagonist propranolol (intratracheal instillation of $10^{-4} \mathrm{M}$ propranolol combined with $3 \mathrm{mg} / \mathrm{kg}$ i.p.) with or without BAY 60-6583 $\left(10^{-3} \mathrm{M}\right.$ to the instilled fluid) or in the presence or absence of the $\beta$-adrenergic agonist zinterol (intratracheal, $10^{-7} \mathrm{M}$ ). ${ }^{*} P<0.01$ compared with no propranolol (C) or zinterol (D), by ANOVA with Bonferroni post-hoc test. $n=8$. In subsets of experiments, either propranoIol or zinterol were added together with BAY 60-6583 $10^{-3} \mathrm{M}$ to the instilled fluid. $\$ P<0.01$ compared with propranolol alone $(\mathbf{C})$ or zinterol alone (D), by ANOVA with Bonferroni post-hoc test. $n=8$.
(13). ALI was induced with mechanical ventilation utilizing high inspiratory pressure levels (e.g., 45 mbar) during pressure-controlled ventilation. In short, animals were anesthetized with pentobarbital $(70 \mathrm{mg} / \mathrm{kg}$ i.p. for induction; $20 \mathrm{mg} / \mathrm{kg} / \mathrm{h}$ for maintenance) and placed on a temperaturecontrolled heated table with a rectal thermometer probe attached to a thermal feedback controller to maintain body temperature at $37^{\circ} \mathrm{C}$. In addition, all animals were monitored with an electrocardiogram (Hewlett Packard). Fluid replacement was performed with normal saline, $0.05 \mathrm{ml} / \mathrm{h}$ i.p. Tracheotomy and mechanical ventilation was performed as described previously (10). In short, the tracheal tube was connected to a mechanical ventilator (Siemens Servo 900C, with pediatric tubing). Mice were ventilated in a pressure-controlled ventilation mode at the inspiratory pressure levels and over the time periods indicated in the figure legends. Respiratory rate and inspiratory/expiratory time ratios were adjusted based on arterial blood gas sampling obtained by cardiac puncture in control animals to maintain a carbon dioxide partial pressure between 35 and $40 \mathrm{mmHg}$ and a pH between 7.35 and 7.40. All animals were ventilated with $100 \%$ inspired oxygen except during experiments to determine a potential influence of the inspired oxygen concentration on A2BAR transcription. In subsets of experiments, mice were treated with the A2BAR antagonist PSB1115 (10 mg/kg i.p.; Tocris) or the A2BAR agonist BAY 60-6583 (2 mg/kg i.p.; Bayer Healthcare), the A1AR antagonist DPCPX (1 mg/kg i.p.; Tocris), the A3AR antagonist MRS1191 (1 mg/kg i.p.; Sigma-Aldrich), amiloride $\left(10^{-3} \mathrm{M}\right.$, $300 \mu \mathrm{l}$ intratracheally; Sigma-Aldrich), or zinterol $\left(10^{-7} \mathrm{M}, 300 \mu \mathrm{l}\right.$ intratracheally; Tocris); or vehicle (13). In subsets of experiments, mice were ventilated under general anesthesia until a cardiac standstill was observed in the surface electrocardiogram. In preliminary studies, we assessed hemodynamic parameters during the above ventilator regiment. Such hemody- namic measurements during a ventilation period of $360 \mathrm{~min}$ revealed no significant changes in heart rate or blood pressure (Supplemental Tables 1 and 2). In contrast, pulmonary gas exchange was significantly attenuated (Supplemental Figure 4). These studies suggest that lung injury in this model is predominantly confined to the lungs and death did not occur due to significant hemodynamic effects.

LPS-induced lung injury. To study endotoxin-induced lung injury, mice were exposed to aerosolized LPS in a custom-built cylindrical chamber connected to an air nebulizer (MicroAir; Omron Healthcare Inc.). The outlet of the chamber was connected to a vacuum pump, and a constant flow rate of $15 \mathrm{ml} / \mathrm{min}$ was ensured by a flow meter (Gilmont Instruments). LPS from E. coli (Sigma-Aldrich) was dissolved in $0.9 \%$ saline $(500 \mu \mathrm{g} / \mathrm{ml})$, and mice were allowed to inhale LPS for $30 \mathrm{~min}$. Control mice were exposed to saline aerosol.

Transcriptional analysis. To examine the influence of mechanical ventilation on A2BAR transcript levels, C57BL/6J mice (Charles River Laboratories) were ventilated in a pressure-controlled fashion using the settings indicated in the figure legends. Mice were euthanized at the time points indicated in the figure legends, and the remaining blood was removed from the pulmonary circulation by injection of $1 \mathrm{ml}$ of PBS into the right ventricle. Lungs were excised and immediately frozen at $-80^{\circ} \mathrm{C}$ until transcriptional profiling. For this purpose, total RNA was isolated using the total RNA isolation NucleoSpin RNA II kit (Macherey \& Nagel) as described previously $(12,13,16)$. RNA was washed, and the concentration was quantified. cDNA synthesis was performed using reverse transcription according to the manufacturer's instructions (i-Script kit; Bio-Rad). The primer sets for the RT-PCR reaction contained $1 \mu \mathrm{M}$ sense and $1 \mu \mathrm{M}$ antisense with SYBR Green I (Invitrogen). Primer sets (shown as sense, antisense, and 
transcript size) for the following genes were: A1AR (5'-AGGGAGGGGTCAAGAACTGT-3', 5'-TCCCAGTCTCTGCCTCTGTT-3', 109 bp), A2AAR (5'-GAAGACCATGAGGCTGTTCC-3', 5'-GAGTATGGGCCAATGGGAGT-3', 253 bp), A2BAR (5'-GGAAGGACTTCGTCTCTCCA-3', 5'-GGGCAGCAACTCAGAAAACT-3', 322 bp), and A3AR (5'-CAATTCGCTCCTTCTGTTCC-3', 5'-TCCCTGATTACCACGGACTC-3', 334 bp). Each target sequence was amplified using increasing numbers of cycles of $94^{\circ} \mathrm{C}$ for $1 \mathrm{~min}, 58^{\circ} \mathrm{C}$ for $0.5 \mathrm{~min}, 72^{\circ} \mathrm{C}$ for $1 \mathrm{~min}$. Murine $\beta$-actin mRNA (sense, $5^{\prime}$-ACATTGGCATGGCTTTGTTT-3' , antisense, 5' -GTTTGCTCCAACCAACTGCT- $3^{\prime}$ ) was amplified in identical reactions to control for the amount of starting template. Levels of, and fold change in, mRNA were determined as described previously $(10,13,65)$.

Immunoblotting experiments. In subsets of experiments, we determined A2BAR protein content from whole lungs. For this purpose, C57BL/6J mice (Charles River Laboratories) were ventilated with the ventilator settings indicated in the figure legends and euthanized. Remaining blood was removed from the pulmonary circulation by injection of $1 \mathrm{ml}$ of PBS into the right ventricle. The lungs were excised and immediately frozen at $-80^{\circ} \mathrm{C}$ until immunoblotting. For this purpose, tissues were homogenized and lysed for $10 \mathrm{~min}$ in ice-cold lysis buffer $\left(10^{7}\right.$ polymorphonuclear neutrophils $/ 500 \mu l ; 150 \mathrm{mM} \mathrm{NaCl}, 25 \mathrm{mM}$ Tris, pH 8.0, $5 \mathrm{mM}$ EDTA, $2 \%$ Triton X-100, and $10 \%$ mammalian tissue protease inhibitor cocktail; Sigma-Aldrich) and collected into microfuge tubes. After spinning at $14,000 \mathrm{~g}$ to remove cell debris, the pellet was discarded. Proteins were solubilized in reducing Laemmli sample buffer and heated to $90^{\circ} \mathrm{C}$ for $5 \mathrm{~min}$. Samples were resolved on a $12 \%$ polyacrylamide gel and transferred to nitrocellulose membranes. The membranes were blocked for $1 \mathrm{~h}$ at room temperature in PBS supplemented with $0.2 \%$ Tween 20 (PBS-T) and $4 \%$ BSA. The membranes were incubated in $10 \mu \mathrm{g} / \mathrm{ml} \mathrm{A2BAR} \mathrm{goat}$ polyclonal antibody raised against the C-terminus (Santa Cruz Biotechnology Inc.) for $1 \mathrm{~h}$ at room temperature, followed by 10 -min washes in PBS. The membranes were incubated in 1:3,000 donkey anti-goat HRP (Santa Cruz Biotechnology Inc.). The wash was repeated, and proteins were detected by enhanced chemiluminescence.

Immunohistochemistry. To examine the influence of mechanical ventilation on pulmonary A2BAR expression, mice were ventilated in a pressure-controlled fashion over the time periods indicated in the figure legends. Mice were euthanized, and the lungs were perfused via the right ventricle with $5 \mathrm{ml}$ of PBS. Lungs were subsequently removed and stained with A2BAR rabbit polyclonal antibody (epitope corresponding to amino acids 293-332 mapping at the $\mathrm{C}$ terminus; Santa Cruz Biotechnology Inc.) as described previously $(10,13,65)$. Isotype controls were used at identical concentrations and staining conditions as the target primary antibodies.

$B A L$ lavage. To obtain BAL fluid, the tracheal tube was disconnected from the mechanical ventilator and the lungs were lavaged 3 times with $0.5 \mathrm{ml}$ of PBS. All removed fluid was centrifuged immediately, and the supernatant was aliquoted for measurement of the albumin concentration.

Measurement of albumin BAL fluid. BAL fluid samples were thawed to $4^{\circ} \mathrm{C}$, and albumin concentrations (Bethyl) were measured using murine quantitative ELISA systems according to the instructions given by the manufacturer. All analyses were made in triplicate, and mean values were used for statistical analysis.

ELISA (IL-6, IL-10, KC, TNF- $\alpha, N F-\kappa B$, and I $\kappa B \alpha)$ from lung tissue. The snapfrozen lungs were thawed, weighed, transferred to different tubes on ice containing $1 \mathrm{ml}$ of Tissue Protein Extraction Reagent (T-PER; Pierce Biotechnology). The lung tissues were homogenized at $4^{\circ} \mathrm{C}$. Lung homogenates were centrifuged at $9,000 \mathrm{~g}$ for $10 \mathrm{~min}$ at $4^{\circ} \mathrm{C}$. Supernatants were transferred to clean microcentrifuge tubes, frozen on dry ice, and thawed on ice. Total protein concentrations in the lung tissue homogenates were determined using a bicinchoninic acid kit (Pierce Biotechnology). Lung tissue homogenates were diluted with 50\% assay diluent and 50\% T-PER reagent to a final protein concentration of $400 \mu \mathrm{g} / \mathrm{ml}$. IL-6 (R\&D Systems), KC (R\&D Systems), IL-10 (R\&D Systems), TNF- $\alpha$ (R\&D Systems), NF-kB (TransAM; Active Motif North America), and IкB $\alpha$ (TransAM; Active Motif North America) levels were evaluated in lung tissue homogenates using a mouse ELISA kit according to the user's manual.

$M P O$ assay. Pulmonary neutrophil sequestration was quantified using a MPO assay as described previously (66-68). In short, animals were euthanized and lungs were perfused with $5 \mathrm{ml}$ of PBS through the right ventricle. Lungs were excised, frozen in liquid nitrogen, lyophilized, mechanically homogenized, and washed in a $50-\mathrm{mM}$ potassium phosphate buffer solution ( $\mathrm{pH}$ 6.0) to remove all hemoglobin. The resulting pellet was resuspended in $1.5 \mathrm{ml}$ of a solution containing hexadecyltrimethylammonium bromide $(5 \mathrm{~g} / \mathrm{l})$. The solution was subjected to 3 cycles of freezing (on dry ice) and thawing (at room temperature), sonicated for $40 \mathrm{~s}$, and centrifuged at $10,000 \mathrm{~g}$ for $5 \mathrm{~min}$ at $4^{\circ} \mathrm{C}$. The supernatant was then assayed for MPO activity using a spectrophotometric reaction with $O$-dianisidine hydrochloride (Sigma-Aldrich). Absorbance at $450 \mathrm{~nm}$ was measured and reported as difference in OD over $5 \mathrm{~min}$.

Wet to dry ratios. Wet to dry ratios were measured as previously described $(27,51)$. In short, following ventilation with indicated settings, lungs were excised en bloc. The weight was obtained immediately to prevent evaporative fluid loss of the tissues. Lungs were than lyophilized for $48 \mathrm{~h}$, and the dry weight was measured. Wet to dry ratios were then calculated as $\mathrm{mg}$ of water per mg of dry tissue.

Blood gas analysis. To assess pulmonary gas exchange, blood gas analyses were performed in subsets of experiments by obtaining arterial blood via cardiac puncture. In short, a lateral thoracotomy was performed to access the left ventricle and blood was obtained via cardiac puncture. Analysis was performed immediately after collection with the I-STAT Analyzer (Abbott), and the arterial partial pressure of oxygen was measured, in addition to arterial partial carbon dioxide pressure and $\mathrm{pH}$ values.

Epinephrine ELISA from plasma. Blood was collected via puncture of the right ventricle. Plasma was stored at $-80^{\circ} \mathrm{C}$ for later analysis after centrifugation $(3,000 \mathrm{~g}, 5 \mathrm{~min})$. Plasma epinephrine concentrations were measured using a commercial radioimmunoassay (Labor Diagnostika Nord) with a sensitivity of $11 \mathrm{pg} / \mathrm{ml}$ and intra- and interassay variabilities of $5 \%$ and $12 \%$, respectively.

Measurement of pulmonary cAMP. cAMP levels in lung homogenate were measured using a competitive immunoassay kit from R\&D Systems.

Measurement of pulmonary PKA activity. PKA activity was determined using a PKA Kinase Activity Assay kit (Assay Designs).

Histopathological evaluation of ALI. Following ventilation at the settings indicated in the figure legends, the mice were euthanized and lungs were fixed by instillation of $10 \%$ formaldehyde solution via the tracheal cannula at a pressure of 20 mbar. Lungs were then embedded in paraffin and stained with hematoxylin and eosin. Two random tissue sections from 4 different lungs in each group were examined by a pathologist who was blinded to the genetic background and treatment of the mice. For each subject, a 5-point scale was applied: 0 , minimal damage; 1 to $>2$, mild damage; 2 to $>3$, moderate damage; 3 to $>4$, severe damage; and $4+$, maximal damage. Points were added together and are expressed as median \pm range $(n=4)$.

Generation of A2BAR bone marrow-chimeric mice. To define the contribution of pulmonary or hematopoietic cell A2BAR to VILI, we generated bone marrow-chimeric mice in which bone marrow was ablated by radiation in WT mice (C57BL/6) followed by reconstitution with bone marrow derived from previously characterized mice gene-targeted for the A2BAR (13) and vice versa $\left(\mathrm{A}_{2} \mathrm{BAR}^{-/-} \rightarrow \mathrm{A}_{2} \mathrm{BAR}^{+/+}\right.$and $\left.\mathrm{A} 2 \mathrm{BAR}^{+/+} \rightarrow \mathrm{A} 2 \mathrm{BAR}^{-/-}\right)$. Experiments with $\mathrm{A} 2 \mathrm{BAR}^{+/+} \rightarrow \mathrm{A}_{2} \mathrm{BAR}^{+/+}$and $\mathrm{A} 2 \mathrm{BAR}^{-/-} \rightarrow \mathrm{A}_{2} \mathrm{BAR}^{-/-}$mice served as con- 
trols. Briefly, male donor mice (8-10 wk old, 20-25 g) were euthanized, and the marrow from the tibia and femur were harvested by flushing the marrow cavity with sterile isotonic $\mathrm{NaCl}$ solution. The bone marrow cells were then centrifuged at $400 \mathrm{~g}$ for $5 \mathrm{~min}$, resuspended, and counted. Recipient mice (8-10 wk of age, 20-25 g) were irradiated with a total dose of $12 \mathrm{~Gy}$ from a ${ }^{137} \mathrm{Cs}$ source. White and red blood count depression after irridiation is shown in Supplemental Table 3. Immediately after irradiation, $10^{7}$ bone marrow cells/recipient were injected in $0.3 \mathrm{ml} 0.9 \% \mathrm{NaCl}$ into the jugular vein. The resulting chimeric mice were housed in microisolators for at least $8 \mathrm{wk}$ before experimentation and fed with water containing tetracycline $(100 \mathrm{mg} / \mathrm{l})$ in the first $2 \mathrm{wk}$ following bone marrow transplantation. Transplantation efficiencies in preliminary experiments using the same conditioning regimen and transplanting CD $45.1^{+}$bone marrow into irradiated CD45.1- mice are displayed in Supplemental Figures 5 and 6. Briefly, to confirm efficiency of reconstitution, a mutated mouse strain, B6.SJL-Ptprca Pep3b/BoyJ, was used as the source of donor bone marrow. The CD45.1 epitope, absent in cells of recipient mice, was detected by immunofluorescent cell analysis $8 \mathrm{wk}$ after bone marrow transplantation. The percentage of cells expressing CD45.1 was determined in each population of cells (Supplemental Figure 5). For this purpose, blood was taken from transplanted recipients and FACS lysing solution (BD Biosciences - Pharmingen) was added to lyse red blood cells. After centrifugation, cells were resuspended in $200 \mu \mathrm{l}$ of PBS containing 1\% BSA. Peripheral blood stem cells were incubated with R-phycoerythrin-conjugated anti-mouse CD45.1 monoclonal antibody (clone A20; BD Biosciences - Pharmingen) in addition to allophycocyanin-conjugated rat anti-mouse CD11b monoclonal antibody (Mac-1 $\alpha$-chain, monocytic cells; BD Biosciences - Pharmingen), rat anti-mouse Ly6G monoclonal antibody (neutrophils; BD Biosciences - Pharmingen), rat anti-mouse B220 monoclonal antibody (B cells; BD Biosciences - Pharmingen), fluorescein isothiocyanate-conjugated rat anti-mouse $\mathrm{CD} 8 \mathrm{a}$ monoclonal antibody $\left(\mathrm{CD}^{+} \mathrm{T}\right.$ lymphocytes; BD Biosciences - Pharmingen), or allophycocyanin-conjugated rat antimouse $\mathrm{CD} 4$ monoclonal antibody $\left(\mathrm{CD}^{+}{ }^{+} \mathrm{T}\right.$ lymphocytes; $\mathrm{BD}$ Biosciences - Pharmingen) on ice for $30 \mathrm{~min}$. $\mathrm{CD} 11 \mathrm{~b}^{+}, \mathrm{CD}^{2} \mathrm{a}^{+}$, and $\mathrm{CD} 4^{+}, \mathrm{B} 220^{+}$, and Ly $6 \mathrm{G}^{+}$cells were sorted by flow cytometry, and the percentage of cells expressing CD45.1 was determined in each population of cells (FACScan, CellQuest; BD). Studies of pulmonary inflammation $8 \mathrm{wk}$ following bone marrow transplantation showed no histological signs of inflammation or neutrophil accumulation (Supplemental Figure 7).

Measurement of AFC during VILI. AFC was assessed in vivo using a previously described technique adapted to measure AFC during VILI $(41,69)$. In short, mice were ventilated in a pressure-controlled ventilation mode at $45 \mathrm{mbar}$ over 0 to $180 \mathrm{~min}$ using an inspired oxygen concentration of $100 \%$. AFC was measured by instilling $300 \mu \mathrm{l}$ of iso-osmolar (320 mOsm) $0.9 \%$ $\mathrm{NaCl}$ solution containing 5\% acid-free BSA (Sigma-Aldrich) via the endotracheal catheter into the alveolar space over $10 \mathrm{~s}$, followed by injection of $100 \mu \mathrm{l}$ of air to achieve complete deposition of all fluid into the alveolar space. Mechanical ventilation was continued for $30 \mathrm{~min}$, at which time the chest was opened to produce bilateral pneumothoraces to facilitate aspiration of the remaining alveolar fluid via the tracheal catheter. Protein concentration was measured using a modified Bradford assay (Bio-Rad). AFC was calculated using the following equation: $\mathrm{AFC}=1-(\mathrm{C} 0 / \mathrm{C} 30)$, where $\mathrm{C} 0$ is the protein concentration of the instillate before instillation and $\mathrm{C} 30$ is the protein concentration of the sample obtained after $30 \mathrm{~min}$ of mechanical ventilation. Clearance is expressed as a percentage of total instilled volume (\%/30 min). Consistent with previous studies, basal mean AFC was $32 \%$ (41). This value was set to $1(100 \%)$. AFC is shown as fold change compared with baseline AFC. In subsets of experiments, amiloride $\left(10^{-3} \mathrm{M}\right)$, PSB1115 $\left(10^{-6} \mathrm{M}\right)$, BAY $60-6583\left(10^{-6} \mathrm{M}\right)$, zinterol $\left(10^{-7} \mathrm{M}\right)$, the CFTR inhibitor $\left(\mathrm{CFTR}_{\text {inh-172, }} 10^{-6} \mathrm{M}\right)$, and propranolol (intratracheal instillation of $10^{-4} \mathrm{M}$ propranolol combined with $3 \mathrm{mg} / \mathrm{kg}$ i.p.) were given together with the instillate. Amiloride sensitivity is reported as fold change of AFC compared with similarly treated mice not exposed to amiloride. In other studies, survival time following intratracheal application of BAY 60-6583 with or without amiloride was determined (see "Murine mechanical ventilation").

Statistics. Lung injury score and survival data are given as median \pm range. All other data are presented as mean \pm SD from 4-6 animals per condition. We performed statistical analysis using the Student's $t$ test $(2$ sided, $\alpha<0.05$ ) or ANOVA to determine group differences. Lung injury score was analyzed with the Kruskal-Wallis rank test. Kaplan-Meier curves were compared using the Mantel-Haenszel log-rank test. $P<0.05$ was considered statistically significant.

\section{Acknowledgments}

This work was supported by grants from the German Research Foundation (DFG; EL274/2-2, to H.K. Eltzschig), the Foundation for Anesthesia Research and Education (to H.K. Eltzschig and T. Eckle), and Interdisciplinary Centre for Clinical Research (IZKF) Nachwuchsgruppe 1605-0-0 (to T. Eckle) and by a DFG Research Fellowship (GR2121/1-1, to A. Grenz). The authors wish to acknowledge Cathrine Ledent, Marlene Jacobson, and Jürgen Schnermann for kindly providing us with gene-targeted mice and Ines Kuhlicke, Stephanie Zug, Marion Faigle, and Katherine Hartmann for technical assistance.

Received for publication October 11, 2007, and accepted in revised form August 13, 2008.

Address correspondence to: Holger K. Eltzschig, Mucosal Inflammation Program, Department of Anesthesiology and Perioperative Medicine, Biochemistry Research Building (BRB), Room 852, 4200 E. 9th Avenue, Mailstop B112, Denver, Colorado 80262, USA. Phone: (303) 315-7320; Fax: (303) 315-0369; E-mail: holger. eltzschig@uchsc.edu.

\section{T. Eckle and A. Grenz contributed equally to this work.}

1. Ware, L.B., and Matthay, M.A. 2000. The acute respiratory distress syndrome. N. Engl. J. Med. 342:1334-1349.

2. Rubenfeld, G.D., et al. 2005. Incidence and outcomes of acute lung injury. N. Engl. J. Med. 353:1685-1693.

3. Belperio, J.A., et al. 2002. Critical role for CXCR2 and CXCR2 ligands during the pathogenesis of ventilator-induced lung injury. J. Clin. Invest. 110:1703-1716.

4. Reutershan, J., Cagnina, R.E., Chang, D., Linden, J., and Ley, K. 2007. Therapeutic anti-inflammatory effects of myeloid cell adenosine receptor A2a stimulation in lipopolysaccharide-induced lung injury.
J. Immunol. 179:1254-1263.

5. Reutershan, J., et al. 2006. Critical role of endothelial CXCR2 in LPS-induced neutrophil migration into the lung. J. Clin. Invest. 116:695-702.

6. Martin, T.R. 2002. Neutrophils and lung injury: getting it right. J. Clin. Invest. 110:1603-1605.

7. Licker, M., et al. 2003. Risk factors for acute lung injury after thoracic surgery for lung cancer. Anesth. Analg. 97:1558-1565.

8. Milot, J., et al. 2001. Incidence and predictors of ARDS after cardiac surgery. Chest. 119:884-888.

9. Shorr, A.F., Abbott, K.C., and Agadoa, L.Y. 2003. Acute respiratory distress syndrome after kidney transplantation: epidemiology, risk factors, and outcomes. Crit. Care Med. 31:1325-1330.

10. Eckle, T., et al. 2007. Identification of ectonucleotidases CD39 and CD73 in innate protection during acute lung injury. J. Immunol. 178:8127-8137.

11. Eckle, T., et al. 2008. A2B adenosine receptor dampens hypoxia-induced vascular leak. Blood. 111:2024-2035.

12. Eckle, T., et al. 2008. Hypoxia-inducible factor-1 is central to cardioprotection: a new paradigm for ischemic preconditioning. Circulation. 118: $166-175$.

13. Eckle, T., et al. 2007. Cardioprotection by ecto-5'nucleotidase (CD73) and $\mathrm{A} 2 \mathrm{~B}$ adenosine receptors. Circulation. 115:1581-1590. 
14. Eltzschig, H.K., et al. 2003. Coordinated adenine nucleotide phosphohydrolysis and nucleoside signaling in posthypoxic endothelium: role of ectonucleotidases and adenosine A2B receptors. J. Exp. Med. 198:783-796.

15. Eltzschig, H.K., et al. 2004. Endogenous adenosine produced during hypoxia attenuates neutrophil accumulation: coordination by extracellular nucleotide metabolism. Blood. 104:3986-3992.

16. Grenz, A., et al. 2008. The reno-vascular A2B adenosine receptor protects the kidney from ischemia. PLoS Med. 5:e137.

17. Fredholm, B.B. 2007. Adenosine, an endogenous distress signal, modulates tissue damage and repair. Cell Death Differ. 14:1315-1323.

18. Ohta, A., and Sitkovsky, M. 2001. Role of G-protein-coupled adenosine receptors in downregulation of inflammation and protection from tissue damage. Nature. 414:916-920.

19. Lankford, A.R., et al. 2006. Effect of modulating cardiac A1 adenosine receptor expression on protection with ischemic preconditioning. Am.J. Physiol. Heart Circ. Physiol. 290:H1469-H1473.

20. Yang, Z., et al. 2005. Infarct-sparing effect of A2Aadenosine receptor activation is due primarily to its action on lymphocytes. Circulation. 111:2190-2197.

21. Yang, D., et al. 2006. The A2B adenosine receptor protects against inflammation and excessive vascular adhesion. J. Clin. Invest. 116:1913-1923.

22. Salvatore, C.A., et al. 2000. Disruption of the A(3) adenosine receptor gene in mice and its effect on stimulated inflammatory cells. J. Biol. Chem. 275:4429-4434.

23. Lappas, C.M., Day, Y.J., Marshall, M.A., Engelhard, V.H., and Linden, J. 2006. Adenosine A2A receptor activation reduces hepatic ischemia reperfusion injury by inhibiting CD1d-dependent NKT cell activation. J. Exp. Med. 203:2639-2648.

24. Linden, J. 2005. Adenosine in tissue protection and tissue regeneration. Mol. Pharmacol. 67:1385-1387.

25. Sitkovsky, M., and Lukashev, D. 2005. Regulation of immune cells by local-tissue oxygen tension: HIF1 alpha and adenosine receptors. Nat. Rev. Immunol. 5:712-721.

26. Sitkovsky, M.V., et al. 2004. Physiological control of immune response and inflammatory tissue damage by hypoxia-inducible factors and adenosine A2A receptors. Ann. Rev. Immunol. 22:657-682.

27. Eltzschig, H.K., et al. 2005. HIF-1-dependent repression of equilibrative nucleoside transporter (ENT) in hypoxia. J. Exp. Med. 202:1493-1505.

28. Mi, T., et al. 2008. Excess adenosine in murine penile erectile tissues contributes to priapism via A2B adenosine receptor signaling. J. Clin. Invest. 118:1491-1501.

29. Sun, D., et al. 2001. Mediation of tubuloglomerular feedback by adenosine: evidence from mice lacking adenosine 1 receptors. Proc. Natl. Acad. Sci. U. S. A. 98:9983-9988.

30. Ledent, C., et al. 1997. Aggressiveness, hypoalgesia and high blood pressure in mice lacking the adenosine A2a receptor. Nature. 388:674-678.

31. Khoury, J., Ibla, J.C., Neish, A.S., and Colgan, S.P. 2007. Antiinflammatory adaptation to hypoxia through adenosine-mediated cullin-1 deneddylation. J. Clin. Invest. 117:703-711.

32. Kumar, A., et al. 2003. Mechanical stretch activates nuclear factor-kappaB, activator protein-1, and mitogen-activated protein kinases in lung parenchyma: implications in asthma. FASEB J. 17:1800-1811.

33. Li, L.F., et al. 2003. Stretch-induced IL-8 depends on c-Jun NH2-terminal and nuclear factor-kap-
paB-inducing kinases. Am. J. Physiol. Lung Cell Mol. Physiol. 285:L464-L475.

34. Chen, Z.J. 2005. Ubiquitin signalling in the NFkappaB pathway. Nat. Cell Biol. 7:758-765.

35. Douillet, C.D., et al. 2005. Mechanical ventilation alters airway nucleotides and purinoceptors in lung and extrapulmonary organs. Am. J. Respir. Cell Mol. Biol. 32:52-58.

36. Lukashev, D.E., et al. 2003. Analysis of A2a receptor-deficient mice reveals no significant compensatory increases in the expression of A2b, A1, and A3 adenosine receptors in lymphoid organs. Biochem. Pharmacol. 65:2081-2090.

37. Thiel, M., et al. 2005. Oxygenation inhibits the physiological tissue-protecting mechanism and thereby exacerbates acute inflammatory lung injury. PLoS Biol. 3:e174.

38. Fredholm, B.B., et al. 1994. Nomenclature and classification of purinoceptors. Pharmacol. Rev. 46:143-156.

39. Comerford, K.M., Lawrence, D.W., Synnestvedt, K., Levi, B.P., and Colgan, S.P. 2002. Role of vasodilator-stimulated phosphoprotein in PKA-induced changes in endothelial junctional permeability. FASEB J. 16:583-585.

40. McAuley, D.F., Frank, J.A., Fang, X., and Matthay, M.A. 2004. Clinically relevant concentrations of beta2-adrenergic agonists stimulate maximal cyclic adenosine monophosphate-dependent airspace fluid clearance and decrease pulmonary edema in experimental acid-induced lung injury. Crit. Care Med. 32:1470-1476.

41. Factor, P., et al. 2007. Adenosine regulation of alveolar fluid clearance. Proc. Natl. Acad. Sci. U. S. A. 104:4083-4088.

42. Kreindler, J.L., and Shapiro, S.D. 2007. Lung turns to AA (adenosine analogues) to dry out. Nat. Med. 13:406-408.

43. Tarran, R., Button, B., and Boucher, R.C. 2006. Regulation of normal and cystic fibrosis airway surface liquid volume by phasic shear stress. Annu. Rev. Physiol. 68:543-561.

44. Mutlu, G.M., et al. 2005. Interdependency of betaadrenergic receptors and CFTR in regulation of alveolar active $\mathrm{Na}+$ transport. Circ. Res. 96:999-1005.

45. Pittet, J.F., et al. 1994. Stimulation of lung epithelial liquid clearance by endogenous release of catecholamines in septic shock in anesthetized rats. J. Clin. Invest. 94:663-671.

46. Su, X., Robriquet, L., Folkesson, H.G., and Matthay, M.A. 2006. Protective effect of endogenous betaadrenergic tone on lung fluid balance in acute bacterial pneumonia in mice. Am. J. Physiol. Lung Cell Mol. Physiol. 290:L769-L776.

47. Yang, D., et al. 2008. The A2b adenosine receptor protects against vascular injury. Proc. Natl. Acad. Sci. U. S. A. 105:792-796.

48. Hasko, G., and Cronstein, B.N. 2004. Adenosine: an endogenous regulator of innate immunity. Trends Immunol. 25:33-39.

49. Lennon, P.F., Taylor, C.T., Stahl, G.L., and Colgan, S.P. 1998. Neutrophil-derived 5'-adenosine monophosphate promotes endothelial barrier function via CD73-mediated conversion to adenosine and endothelial A2B receptor activation. J. Exp. Med. 188:1433-1443.

50. Eltzschig, H.K., Macmanus, C.F., and Colgan, S.P. 2008. Neutrophils as sources of extracellular nucleotides: functional consequences at the vascular interface. Trends Cardiovasc. Med. 18:103-107.

51. Thompson, L.F., et al. 2004. Crucial role for ecto5 '-nucleotidase (CD73) in vascular leakage during hypoxia. J. Exp. Med. 200:1395-1405.

52. Asikainen, T.M., et al. 2005. Activation of hypoxia-inducible factors in hyperoxia through prolyl 4-hydroxylase blockade in cells and explants of primate lung. Proc. Natl. Acad. Sci. U. S. A. 102:10212-10217.

53. Synnestvedt, K., et al. 2002. Ecto-5'-nucleotidase (CD73) regulation by hypoxia-inducible factor- 1 mediates permeability changes in intestinal epithelia. J. Clin. Invest. 110:993-1002.

54. Kong, T., Westerman, K.A., Faigle, M., Eltzschig, H.K., and Colgan, S.P. 2006. HIF-dependent induction of adenosine $\mathrm{A} 2 \mathrm{~B}$ receptor in hypoxia. FASEB J. 20:2242-2250.

55. Laughlin, M.J., Wild, L., Nickerson, P.A., and Matalon, S. 1986. Effects of hyperoxia on alveolar permeability of neutropenic rabbits. J. Appl. Physiol. 61:1126-1131.

56. Raj, J.U., Hazinski, T.A., and Bland, R.D. 1985. Oxygen-induced lung microvascular injury in neutropenic rabbits and lambs. J. Appl. Physiol. 58:921-927.

57. Blackburn, M.R. 2003. Too much of a good thing: adenosine overload in adenosine-deaminase-deficient mice. Trends Pharmacol. Sci. 24:66-70.

58. Chunn, J.L., et al. 2005. Adenosine-dependent pulmonary fibrosis in adenosine deaminase-deficient mice. J. Immunol. 175:1937-1946.

59. Sun, C.X., et al. 2006. Role of A2B adenosine receptor signaling in adenosine-dependent pulmonary inflammation and injury. J. Clin. Invest. 116:2173-2182.

60. Sun, C.-X., et al. 2005. A protective role for the A1 adenosine receptor in adenosine-dependent pulmonary injury. J. Clin. Invest. 115:35-43.

61. Driver, A.G., Kukoly, C.A., Ali, S., and Mustafa, S.J 1993. Adenosine in bronchoalveolar lavage fluid in asthma. Am. Rev. Respir. Dis. 148:91-97.

62. Huszar, E., et al. 2002. Adenosine in exhaled breath condensate in healthy volunteers and in patients with asthma. Eur. Respir. J. 20:1393-1398.

63. Fozard, J.R., and Hannon, J.P. 1999. Adenosine receptor ligands: potential as therapeutic agents in asthma and COPD. Pulm. Pharmacol. Ther. 12:111-114.

64. Blackburn, M.R., et al. 2000. Metabolic consequences of adenosine deaminase deficiency in mice are associated with defects in alveogenesis, pulmonary inflammation, and airway obstruction. J. Exp. Med. 192:159-170.

65. Kohler, D., et al. 2007. CD39/ectonucleoside triphosphate diphosphohydrolase 1 provides myocardial protection during cardiac ischemia/reperfusion injury. Circulation. 116:1784-1794.

66. Speyer, C.L., et al. 2005. Regulatory effects of estrogen on acute lung inflammation in mice. Am.J. Physiol. Cell Physiol. 288:C881-C890.

67. Graff, G., Gamache, D.A., Brady, M.T., Spellman, J.M., and Yanni, J.M. 1998. Improved myeloperoxidase assay for quantitation of neutrophil influx in a rat model of endotoxin-induced uveitis. J. Pharmacol. Toxicol. Methods. 39:169-178.

68. Schneider, T., and Issekutz, A.C. 1996. Quantitation of eosinophil and neutrophil infiltration into rat lung by specific assays for eosinophil peroxidase and myeloperoxidase. Application in a Brown Norway rat model of allergic pulmonary inflammation. J. Immunol. Methods. 198:1-14.

69. Mutlu, G.M., et al. 2004. Upregulation of alveolar epithelial active $\mathrm{Na}+$ transport is dependent on beta2-adrenergic receptor signaling. Circ. Res. 94:1091-1100 